\title{
UNA DÉCADA DE GUERRA EN SIRIA: SITUACIÓN ACTUAL Y POSIBLES DESENLACES
}

\author{
Andrea Cocchini ${ }^{1}$ \\ Universidad de Navarra
}

\begin{abstract}
Resumen:
En este año 2021 se cumplen diez años del comienzo del conflicto armado en Siria que, desencadenado por unos grafitis en contra del gobierno guiado con mano autoritaria por la familia al-Assad, se ha convertido en una guerra con, al menos, 390.000 muertos, que ha acabado involucrando a numerosos Estados de Oriente Próximo, así como a grandes potencias, cada una portadora de intereses geopolíticos concretos. El presente artículo pretende dar cuenta de la situación actual de Siria y, en particular, de los objetivos particulares que mantienen en el país diversos actores. Después de que desaparecieran las dos razones principales esgrimidas para intervenir en el conflicto, quedó de manifiesto su auténtica naturaleza de guerra subsidiaria y sectaria, que se inserta en las más amplias contiendas entre rivales históricos como los Estados Unidos y Rusia, por una parte, y Arabia Saudí, Turquía e Irán, por otra, y que ninguno entre ellos parece tener interés en acabar sin recibir compensaciones.
\end{abstract}

Palabras Clave: Siria, Guerra siria, Daesh, Operación Determinación absoluta, Escudo del Eufrates, Irán, Turquía, Arabia Saudí, Rusia, Estados Unidos.

Title in English: A decade of war in Syria: current situation and possible outcomes

Abstract:

This year 2021 marks the tenth anniversary of the beginning of the armed conflict in Syria which, triggered by graffiti against the government of the al-Assad family, turned into a civil war with at least 390,000 dead, involving numerous States in the Middle East, as well as the major global powers, with their own specific geopolitical interests. This article therefore aims to provide an account of the current situation in Syria and the objectives that these powers still have in this country. Once the two main reasons for intervening in the conflict disappeared, the true nature of this war came to the surface, embedded in the broader contests of historical rivalry between the United States and Russia on the one hand, and Saudi Arabia, Turkey and Iran on the other. Apparently, none of them really wants to end it, without compensation

Key wrods: Syria, Syrian War, Daesh, Operation Inherent Resolve, Euphrates Shield, Peace Fountain, Iran, Turkey, Saudi Arabia, Russia, United States.

Copyright (C) UNISCI, 2021.

Las opiniones expresadas en estos artículos son propias de sus autores, y no reflejan necesariamente la opinión de UNISCI. The views expressed in these articles are those of the authors, and do not necessarily reflect the views of UNISCI

\footnotetext{
${ }^{1}$ Andrea Cocchini es Profesor ayudante doctor (acreditado contratado doctor) de Derecho Internacional Público y de la Unión Europea en la Universidad de Navarra

E-mail: <acocchini@unav.es>

DOI: http://dx.doi.org/10.31439/UNISCI-124
} 


\section{Introducción ${ }^{2}$}

Han pasado ya más de diez años desde que unas manifestaciones pacíficas lideradas por jóvenes sirios cansados de vivir bajo un gobierno opresor, uniéndose al movimiento de la "Primavera árabe" que había logrado en las semanas anteriores acabar con regímenes autoritarios en varios países del norte de África, ${ }^{3}$ se convirtieran en un conflicto armado interno, antes, y una pugna internacional para el control del país, después. En marzo de 2011, en una ciudad del suroeste de Siria de apenas cien mil habitantes, Daraa, comenzaron unas protestas pacíficas contra el encarcelamiento de algunos jóvenes culpables de pintar unos grafitis contra el régimen, por su corrupción rampante, las altas tasas de desempleo y la falta de libertades políticas bajo el régimen del presidente Bashar al-Assad, hijo de Hafez, fallecido en 2000. Sin embargo, cuando las fuerzas gubernamentales sirias respondieron con las armas para disolver a los manifestantes, la indignación ciudadana estalló en todo el país, pidiendo las dimisiones de al-Assad cuya respuesta fue una represión todavía más violenta de lo que definió "terrorismo respaldado desde el extranjero". De ahí a la detonación de una auténtica guerra civil el paso fue muy breve, así como breve fue el tiempo necesario para que otros Estados se inmiscuyesen en el conflicto y que, en una situación de caos total, emergiesen otros actores no estatales interesados en repartirse el territorio sirio, como el Daesh (el acrónimo árabe para "Estado Islámico de Iraq y el Levante"), al-Qaeda y otras organizaciones terroristas menores. Se estima que, hasta diciembre de 2020, murieron casi 390.000 personas, de las que, cerca de 120.000, eran civiles; además, 205.000 individuos resultaban desaparecidos y, presuntamente, fallecidos. ${ }^{4}$ Los mayores responsables de todas estas víctimas resultan ser, con diferencia respecto a las demás partes beligerantes, las fuerzas gubernamentales de Siria (156.329 muertos), seguidas por los distintos grupos rebeldes (34.606 fallecidos) y el Daesh (13.996 víctimas). ${ }^{5}$ Tras una década de conflicto, el $95 \%$ de la población civil siria no tiene acceso a los cuidados sanitarios de base, un $70 \%$ ni siquiera al agua potable y más de 13 millones de habitantes (sobre una población total previa al conflicto de 22 millones) necesitan asistencia humanitaria. De estos, más de 6.7 millones de personas son desplazados internos y unos 6.6 millones huyeron del país, encontrando en su amplia mayoría refugio en los Estados limítrofes de Jordania, Turquía, Iraq, Líbano y Egipto. ${ }^{6}$ El país vive hoy una crisis económica espantosa debido a la guerra, a las sanciones internacionales, a la descarada corrupción gubernamental, al colapso de los bancos libaneses (en donde muchos sirios pudientes guardaban sus ahorros) ${ }^{7}$ y a la pandemia de COVID-19 que ha puesto bajo presión un sistema sanitario ya de por sí destrozado de estos años de guerra (solo la mitad de los hospitales del país funciona con regularidad). ${ }^{8}$ Todo ello

\footnotetext{
${ }^{2}$ Agradezco a los catedráticos Romualdo Bermejo García y Antonio Marquina Barrio por querer contar conmigo para este número de la Revista y por sus valiosas revisiones y sugerencias.

3 Taub, Amanda: "The Unsexy Truth about Why the Arab Spring failed", Vox, 27 February 2016, en https://www.vox.com/2016/1/27/10845114/arab-spring-failure

4 “On International Human Rights Day: Millions of Syrians deprived from their basic rights, and 593.000 people killed in nearly a decade of the Syrian Revolution”, Syrian Observatory for Human Rights, 9 December 2020, en https://www.syriahr.com/en/195385/

5 “Annual Statistical Report on Casualties in Syria 2020”, Violations Documentation Center, pp. 1-7, p. 3, en https://scm.bz/en/violations-watch/vdc-annual-statistical-report-on-casualties-in-syria

${ }^{6}$ UNHCR, Syria Refugee Crisis Explained, 5 February 2021, en https://www.unrefugees.org/news/syria-refugee-crisis-explained

${ }^{7}$ Barthelmess, Benedikt y Carson, Liam: "How is the crisis in Lebanon impacting Syria's economy?", Middle East Institute, 28 August 2020, en https://www.mei.edu/publications/how-crisis-lebanon-impacting-syrias-economy 8 "La Siria, dieci anni dopo", Il Post, 15 marzo 2021, en https://www.ilpost.it/2021/03/15/guerra-in-siria-diecianno/
} 
ha provocado un aumento vertiginoso en los precios de bienes esenciales y la caída vertical del valor de la Libra siria, reduciendo al $90 \%$ de la población en condiciones de pobreza. ${ }^{9}$

Frente a esta situación, de los 22 millones de habitantes que vivían en Siria antes de 2011, la mitad tuvo que abandonar sus casas: 6.7 millones son desplazados internos, mientras que los otros 5.6 millones resultan registrados como refugiados en el extranjero. Turquía (3.655.067 refugiados), Líbano (865.531 personas) y Jordania (664.603 individuos) acogen por sí solas el 93\% de ellos. Hoy en día, el gobierno de al-Assad ha vuelto a controlar cerca de dos tercios del país y a ejercer su poder en las ciudades más importantes, aunque tiene entre manos un Estado muy diferente al que existía hace diez años, en donde quedan todavía importantes focos de resistencia de grupos terroristas yihadistas, grupos rebeldes y tropas kurdas de las Fuerzas Democráticas Sirias (FDS) que se reparten la franja norte del país. Mientras la zona noroccidental de Siria está en manos de milicias yihadistas, con la importante excepción de la ciudad de Idlib, la parte nororiental de Siria está ocupada en buena parte por las fuerzas kurdas, enfrentadas con el ejército turco y sus grupos de apoyo. ${ }^{10} \mathrm{~A}$ esto se añade la zona sur, la provincia drusa de Daraa y la provincia de Quneitra y sus alrededores, donde, a pesar del acuerdo de 2018, Damasco ha consolidado su presencia en la zona en los últimos meses, no admitiendo seguir compartiendo el poder con otros grupos armados.

Figura 1. Siria: Zonas de Influencia en 2020

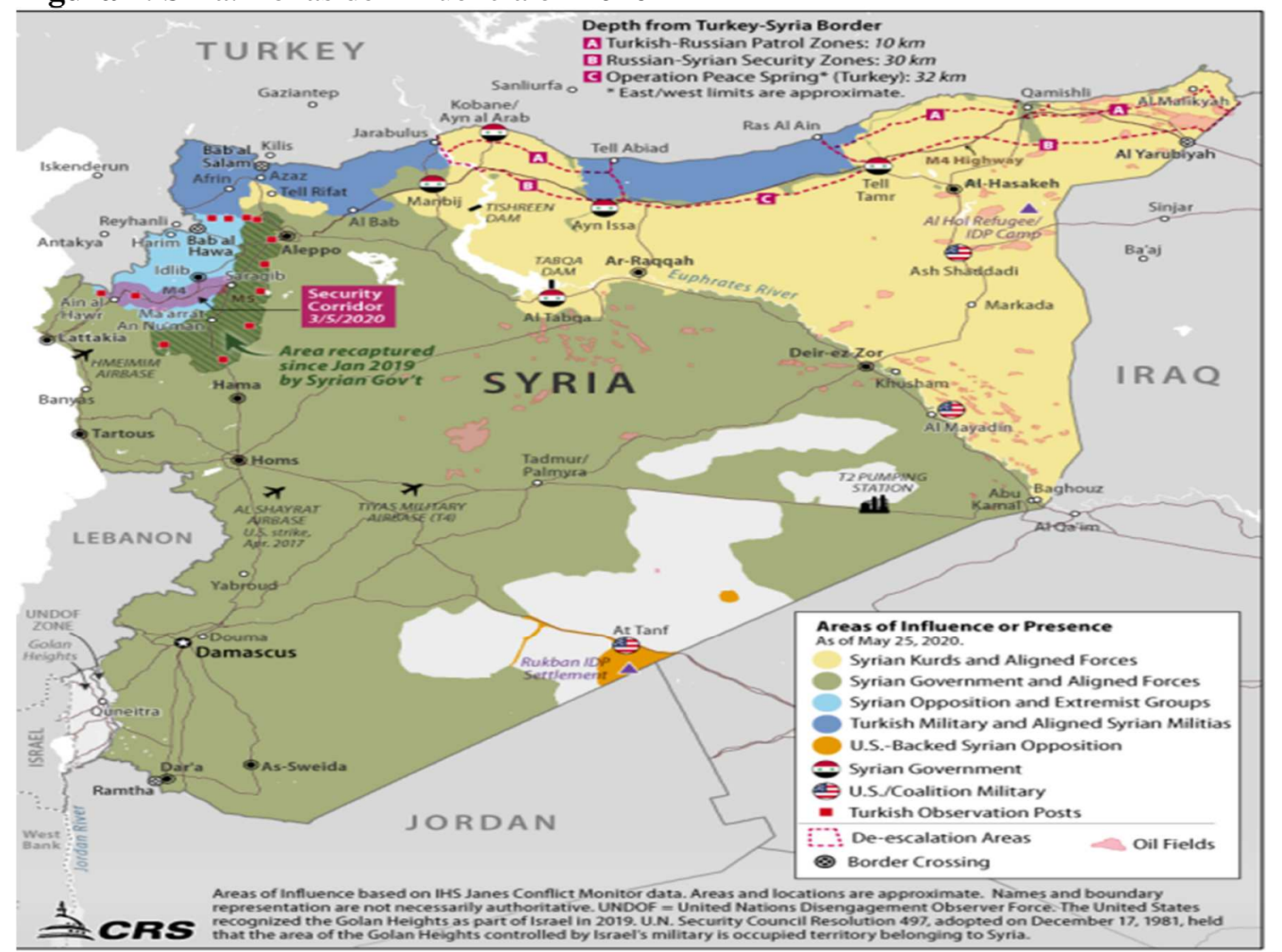

De lo que pretendía ser un "Estado islámico" queda muy poco después de que las milicias del Daesh tuviesen que retirarse en el interior del país, tras perder su último baluarte en la batalla de Baghuz de 2019. En consecuencia, no parece exagerado hablar de una "balcanización" de

\footnotetext{
${ }^{9}$ Lister, Charles: "2021 will be a defining year for Syria", Middle East Institute, 12 January 2021, en https://www.mei.edu/publications/2021-will-be-defining-year-syria

10 "Why has the Syrian war lasted 10 years?", BBC News, 12 March 2021, en https://www.bbc.com/news/worldmiddle-east-35806229
} 
Siria, en donde cada área cuenta con el apoyo de una potencia extranjera, posee sus propias milicias, su economía y favorece un determinado grupo étnico o religioso. ${ }^{11}$

¿Puede decirse, entonces, que el conflicto sirio está en vías de finalización? Lo que tenemos más que comprobado en estos diez años de guerra es que es posible liquidar impunemente a la población civil, recurriendo a las armas químicas de destrucción masiva, a las bombas racimo, a los barriles explosivos e, incluso, al sitio de ciudades reducidas a la hambruna, sin más consecuencias que manifestaciones condenatorias y discursos altisonantes. Todo ello, obviamente, en flagrante violación de las más elementales reglas del jus ad bellum y del jus in bello internacionales, así como de los diferentes pactos estipulados entre los actores involucrados, "en un constante ejercicio de injerencia interna en el que tanto potencias regionales como globales se han podido mover a sus anchas". ${ }^{12}$

La respuesta a esta pregunta necesita de un análisis previo de la dimensión tanto interna como internacional de la guerra, ya que a los intereses nacionales de las facciones en lucha se suman y mezclan los objetivos geopolíticos de las potencias regionales y mundiales involucradas en el polvorín sirio. El propósito del presente artículo es intentar dar una respuesta al interrogante arriba planteado, con base en la observación de las políticas adoptadas por los Estados protagonistas en esta contienda sobre el futuro de Siria. Para ello, en el apartado 2, se repasarán las posturas de algunos de estos Estados frente a la dictadura de al-Assad y sus consecuentes posicionamientos en el conflicto interno. En particular, se hará hincapié en el bando que algunos de ellos decidieron tomar cuando empezó la operación militar Determinación absoluta (Inherent Resolve), la campaña militar comenzada por iniciativa de los Estados Unidos cuyo objetivo principal era eliminar la amenaza que la organización terrorista del Daesh representaba para Oriente Próximo y el Occidente. Después de ello, en el apartado 3 se profundizará en sí y cómo la derrota casi total de este grupo yihadista haya supuesto un cambio en las estrategias y en los objetivos de estos países. En concreto, en el subapartado 3.1, se analizarán las motivos originarios y hodiernos de los principales Estados de Oriente Próximo involucrados en la cuestión siria. Por otra parte, en el sucesivo subapartado 3.2, se comentarán las causas que determinaron la involucración de las dos potencias globales, los Estados Unidos y Rusia, en la guerra de Siria y las razones por las que siguen (o ya no siguen) combatiendo en el país. Por último, en el apartado 4, se ofrecerán algunas consideraciones conclusivas que intentarán responder a la pregunta con la que comenzamos este artículo.

\section{El surgimiento de DAESH}

Hace cuatro años ${ }^{13}$ podíamos hablar de una organización terrorista cuya base originaria se encontraba en una porción amplia del territorio sirio e iraquí y cuyas ramificaciones abrazaban buena parte del globo, yendo de los Balcanes hasta el Sudeste asiático, pasando por el Cáucaso, el Magreb, el Sahel, la Península Arábiga y Asia central. ${ }^{14}$ Se ha calculado que, en su ápice, el

\footnotetext{
11 "La Siria, dieci anni dopo", op. cit.

12 Ibid.

${ }^{13}$ Cocchini, Andrea: “El Estado Islámico y la geopolítica: el enemigo de mi enemigo es mi amigo... ¿o no?”, en Gutiérrez Espada, Cesáreo y Cervell Hortal, María José (dirs.) (2018): El Estado Islámico (Daesh): ¿Aprenderemos la lección?, Valencia, Tirant lo Blanch, pp. 45-92.

${ }^{14}$ Echeverría Jesús, Carlos: "El desafío terrorista de Boko Haram en Nigeria", Instituto Español de Estudios Estratégicos, Documento de investigación, $\mathrm{n}^{\circ} \quad 2 \quad$ (2014), $\quad$ pp. $1-17$, en http://www.ieee.es/Galerias/fichero/docs_investig/2014/DIEEEINV02-

2014_Region_Africa_subsahariana_C.Echeverria.pdf; González Francisco, Luis: "Wilāyat Saynā': la 'provincia' de Daesh en el Sinaí egipcio", Instituto Español de Estudios Estratégicos, Documento de opinión, no 81 (2016), pp. 1-14; Gunaratna, Rohan: "Global Terrorism in 2016", Revista UNISCI, no 40 (2016), pp. 133-138, p. 136; Jordán Enamorado, Javier: "Introducción”, Instituto Español de Estudios Estratégicos, Cuadernos de Estrategia, $\mathrm{n}^{\mathrm{o}} 180$ (2016), pp. 9-19, p. 10, en https://www.uma.es/foroparalapazenelmediterraneo/wpcontent/uploads/2016/10/ce-180-estrategia-para-derrotar-al-daesh.pdf
} 
Daesh podía contar con alrededor de 80.000 combatientes terroristas, entre los cuales unos 20.000 no eran ni sirios ni iraquíes, a los que, además, había que sumar las decenas de miles de secuaces en el resto del mundo. ${ }^{15}$ Tanto es así que algunos autores llegaron a avanzar la propuesta de que el Daesh estaba convirtiéndose en un verdadero Estado, de igual manera que, en su día, hicieron Estados revolucionarios como la antigua Unión Soviética o la República Popular de China. ${ }^{16}$ Los acontecimientos sucesivos mostraron que, por suerte, así no era y que el Daesh nació y se quedó siempre como una organización terrorista, pese a la extensión y el poder, económico y militar, que llegó a alcanzar en los años de 2013 a 2015, sobre todo.

Como ya es sabido, el Daesh es una organización yihadista salafista, ${ }^{17}$ que se originó de la rama iraquí de al-Qaeda y trae su naturaleza radical de un conjunto de variables sociopolíticas y étnico-religiosas, ${ }^{18}$ por lo que perpetra el llamado "yihad menor" ${ }^{19}$ tanto contra los musulmanes chiíes y sunníes moderados, como contra los no musulmanes. ${ }^{20}$ Más en concreto, el origen del Daesh se remonta al año 2003, cuando los Estados Unidos comenzaron la invasión de Iraq con la operación Libertad iraquí. ${ }^{21}$ Con el desplome del régimen dictatorial de Saddam Hussein, asistimos a un pasaje de poderes de las manos de los sunníes a las de los chíes, lo que determinó que el chií Nouri al-Maliki se hiciese con el gobierno de Iraq, desde 2006 hasta 2014, cuando le sucedió Haider al-Abadi. El primero, se hizo responsable de una política nacional revanchista y abiertamente hostil a los sunníes que vinieron así alejados de cualquier cargo institucional. Se alimentaron, en consecuencia, las ya existentes tensiones político-religiosas,

\footnotetext{
${ }^{15}$ Gunaratna, op. cit., p. 134.

${ }^{16}$ Cronin, Audrey Kurth: "ISIS Is Not a Terrorist Group: Why Counterterrorism Won't Stop the Latest Jihadist Threat", Foreign Affairs, vol. 94, no 2 (2015), pp. 87-98, en particular pp. 88 y 91; Fillingham, Zachary: "Is Islamic State a State?", Geopolitical Monitor, 5 August 2015, en https://www.geopoliticalmonitor.com/is-islamic-state-astate/; Martín Rodríguez, Javier (2015): Estado Islámico: Geopolítica del caos, Madrid, Catarata, p. 15; Ortega, Andrés: "El califato, una idea con territorio", Real Instituto Elcano, Blog Elcano, 7 de julio de 2015, en http://www.blog.rielcano.org/el-espectador-global-califato-una-idea-territorio/; Walt, Stephen M.: "ISIS as Revolutionary State: New Twist on an Old Story", Foreign Affairs, November/December 2015, en https://www.foreignaffairs.com/articles/middle-east/isis-revolutionary-state

17 Barker, Brig: "ISIS: Nothing New Under The Sun", Journal of Counterterrorism \& Homeland Security International, vol. 20, $\mathrm{n}^{\circ} 4$ (2014), pp. 10-12; González Hernández, Manuel: "Definiendo términos: fundamentalismo, salafismo, sufismo, islamismo, wahabismo", Instituto Español de Estudios Estratégicos, Documento de opinión, ${ }^{\circ} 88$ (2015), pp. 1-12, en

http://www.ieee.es/Galerias/fichero/docs_opinion/2015/DIEEEO88-Antiislamismo_MGlezHdez.pdf

${ }^{18}$ Rooney, Mildred: "El 'Estado Islámico': la ruta a la autoproclamación de un califato contemporáneo", Agenda Internacional, vol. 34 (2016), pp. 49-76, p. 63.

${ }^{19}$ Bramon, Dolors: "La confusión del 'jihad"”, IEMed. Focus Article, vol. 113 (2014), pp. 2-3, en particular, p. 1, que explica la diferencia entre la yihad mayor (o "de las almas"), el esfuerzo pedido a todo musulmán para mejorarse como creyente, y la yihad menor (o "de los cuerpos"), el esfuerzo para extender el islam al resto del mundo, convirtiendo o sometiendo a los no musulmanes, en https://www.iemed.org/observatori/areesdanalisi/arxius-adjunts/copy_of_focus/113-jihad.pdf

${ }^{20}$ Smith, Amelia: "Iraqi vice-president on Sunni oppression, Nouri al-Maliki and sectarian division", Middle East Monitor, 28 de agosto 2014, en https://www.middleeastmonitor.com/20140828-iraqi-vice-president-on-sunnioppression-nouri-al-maliki-and-sectarian-division/; la organización Iraq Body Count estima que desde 2003 en Iraq han muerto 288.000 individuos, entre civiles y combatientes. En particular, el año 2013 registró 9.851 fallecidos entre los civiles, mientras que el 2014 se concluyó con 20.035 civiles muertos, mostrando un aumento esperpéntico en correspondencia del auge de la organización terrorista del Daesh. A partir de 2018, con la inflexión de la virulencia de las acciones armadas del Daesh, los números de fallecidos empezaron a bajar gradualmente, hasta llegar a las 902 víctimas de 2020, en https://www.iraqbodycount.org/database/ (Último acceso: 20 de abril de 2021)

${ }^{21}$ Asseburg, Muriel: "All Eyes on the Islamic State? Repercussions of the Fight against Jihadists on War-Torn Syria”, IEMed., Mediterranean Yearbook (2015), pp. 1-4, p. 1, en https://www.iemed.org/observatori/areesdanalisi/arxius-

adjunts/anuari/med.2015/IEMed_MedYearbook2015_All_Eyes_on_the_Islamic_State_Muriel\%20Asseburg.pdf; Martín Rodríguez, op. cit., p. 33; Ortega, Andrés: “Evitar un Estado Islámico 2.0”, Real Instituto Elcano, Blog Elcano, 18 de julio de 2017, en http://www.blog.rielcano.org/evitar-un-estado-islamico-2-0/
} 
aumentando la fragilidad de las instituciones democráticas y la propagación de las violencias sectarias.

En 2011, con la retirada del ejército estadounidense del Iraq, resultó claro de inmediato que las fuerzas regulares iraquíes no podían preservar la estabilidad y la seguridad internas en el país. Por tanto, en una atmósfera cada vez más hostil al presidente chií al-Maliki, el Daesh pudo extenderse y prosperar, en particular en las áreas desérticas de la región occidental iraquí de al-Anbar. ${ }^{22}$ A mediados de 2014, el antiguo jefe y guía espiritual del Daesh, Abu Bakr alBaghdadi (muerto en octubre de 2019 durante una misión estadounidense en la provincia siria de Idlib) podía así proclamar durante un sermón en la mezquita de al-Nuri de Mosul, la tercera ciudad más poblada de Iraq, la creación de un nuevo califato. ${ }^{23}$

Estos acontecimientos favorecieron la expansión de la banda terrorista también en Siria, ya sumergida de lleno en su guerra civil, en contra del gobierno de al-Assad, miembro de la élite chií de los alauíes dentro de un Estado mayoritariamente sunní. También en Siria, el Daesh logró afirmarse sobre los demás grupos rebeldes, tomando así numerosos distritos en la zona noreste del país, especialmente ricos en pozos petrolíferos. En su época de máxima abundancia y desarrollo, se cree que la organización ocupaba un territorio de alrededor de $90.800 \mathrm{~km}^{2}$ (parecido a las dimensiones de Portugal) y que consiguiera entre uno y tres millones de dólares al día, dinero procedente, en su mayoría, de la extracción de crudo y de su sucesiva exportación a Turquía y comercialización en el mercado negro. ${ }^{24}$ Sin embargo, a partir de 2016, el Daesh comenzó su inexorable parábola descendente. Este declive se debe sin duda al éxito militar de la operación Determinación absoluta, comenzada oficialmente en octubre de 2014 y todavía activa, que reúne una coalición de 83 Estados encabezados por los Estados Unidos con la misión de derrotar a la organización y evitar su restauración futura. Esta campaña se desarrolla en cuatro fases. En la primera, concluida a finales de 2015, la coalición realizó bombardeos aéreos contra los emplazamientos del Daesh en Iraq y en Siria, entrenando y equipando a las fuerzas terrestres iraquíes, sirias y kurdas. En la segunda fase, respaldó las fuerzas de seguridad de Iraq y algunos grupos rebeldes en Siria empeñados en liberar los territorios y las poblaciones sujetos al dominio de los terroristas. Durante esta fase, la coalición siguió con el adiestramiento, el equipamiento, el asesoramiento y la asistencia de las fuerzas asociadas. En la tercera fase, la coalición ejecutó diversos ataques en apoyo de las fuerzas terrestres involucradas en las batallas decisivas de Raqqa y Mosul, mermando definitivamente los recursos materiales y psicológicos de los milicianos del Daesh. Desde entonces, las tropas iraquíes y la resistencia siria asociada a la operación Determinación absoluta, luchan para eliminar los focos restantes de resistencia por parte de los terroristas del Daesh en ambos Estados. En la cuarta y última fase de "ayuda a la estabilización", la coalición se encarga de garantizar cierta seguridad, facilitar la planificación y dar el apoyo necesario al gobierno de Iraq y a las "autoridades competentes" en Siria (no obstante, no se específica quiénes deberían ser estas autoridades competentes: ¿alAssad y su Gobierno? ¿Los rebeldes “moderados”?). ${ }^{25}$

\footnotetext{
${ }^{22}$ Echeverría Jesús, Carlos: "El Estado Islámico (EI) como grupo terrorista yihadista salafista y otros grupos armados violentos actuando en Irak hoy", Instituto Español de Estudios Estratégicos, Documento de investigación, $\mathrm{n}^{\mathrm{o}} 6$ (2014), pp. 1-15, p. 5, en http://www.ieee.es/Galerias/fichero/docs_investig/2014/DIEEEINV06-

2014_EstadoIslamico_CarlosEcheverria_.pdf; Martín Rodríguez, op. cit., pp. 56-64.

23 "El EIIL instaura un califato en las zonas que controla en Irak y Siria", El País, 29 de junio de 2014, en https://internacional.elpais.com/internacional/2014/06/29/actualidad/1404044318_360507.html

${ }^{24}$ Wing, Nic y Kolodny, Carina: "15 Shocking Numbers That Will Make You Pay Attention To What ISIS Is Doing In Iraq", The Huffington Post, 11 August 2014, en http://www.huffingtonpost.com/2014/08/11/isis-iraqnumbers_n_5659239.html

${ }^{25}$ Operation Inherent Resolve, en https://www.inherentresolve.mil/campaign/
} 
Por otra parte, no podemos olvidar, al otro lado del tablero, las intervenciones decisivas para el colapso del Daesh realizadas por los otros dos principales protagonistas de la guerra en Siria, Rusia e Irán, que cambiaron decididamente el rumbo del conflicto en favor del régimen de alAssad. En particular, Moscú ha negado siempre su beneplácito a una campaña militar en Siria que pudiese derrocar a al-Assad, como resulta patente de diferentes intervenciones de los representantes rusos en el seno del Consejo de Seguridad de las Naciones Unidas (ONU) que se analizarán más adelante. Es más, en septiembre de 2015, gracias a la coartada de la lucha al Daesh, Rusia lanzó una campaña de bombardeos aéreos en defensa del régimen de Damasco que estaba a punto de desmoronarse. ${ }^{26} \mathrm{~A}$ este respecto, se pueden identificar dos momentos en los que parecía que Bashar al-Assad y su dictadura pudieran caer. El primero, remonta al periodo a caballo de finales de 2012 y principios de 2013, cuando las fuerzas de oposición al régimen consiguieron romper el cordón de seguridad constituido alrededor de la capital, Damasco. ${ }^{27}$ El segundo, se dio en agosto de 2015, cuando los grupos de oposición en el norte de Siria armados por la CIA, realizaron unas incursiones exitosas que estuvieron a punto de desmoronar el ejército regular sirio. Fue entonces cuando el antiguo comandante iraní de la Fuerza Quds (rama en el exterior de la Guardia Revolucionaria de Irán), Qassem Soleimani, viajó hasta Moscú con los mapas del conflicto en mano para mostrarlos al presidente Vladimir Putin, advirtiéndole de que, sin su ayuda, las fuerzas fieles al régimen y el régimen mismo no hubieran aguantado más de tres semanas. Y fue así como, en septiembre de 2015, Rusia empezó su campaña de bombardeos aéreos sobre el territorio sirio. ${ }^{28}$ Decíamos que combatir el Daesh fue el pretexto que el Kremlin usó para justificar, si no jurídicamente (la injerencia militar rusa en Siria es legal desde el punto de vista del Derecho internacional, al contar con el consentimiento del gobierno sirio), al menos políticamente, las incursiones de los cazas rusos en los cielos sirios. Estos, en efecto, tenían como blanco preferente a los principales grupos rebeldes que combaten contra al-Assad, los milicianos del Hayat Tahrir al-Sham (Comité de liberación del Levante o HTS, conocido anteriormente como Jabhat al-Nusra), una organización yihadista salafista aliada con al-Qaeda en Siria (Hurras al-Din u Organización de Guardianes de la fe) y, en menor medida, a los terroristas del Daesh, ${ }^{29}$ puesto que los bombardeos se concentraron sobre todo en el oeste de Siria, bastión del régimen, en donde apenas había milicias del Daesh. ${ }^{30}$ No sorprende, entonces, que el $80 \%$ de las acciones aéreas rusas se dirigiese contra las zonas controladas por los opositores del régimen, algunos de los cuales recibían el apoyo militar de la coalición internacional liderada por los Estados Unidos y reunida en la operación Determinación absoluta. ${ }^{31}$ Sin embargo, hay que subrayar que fue gracias a los

\footnotetext{
26 Bonet, Pilar: "Aviones rusos bombardean en territorio sirio", El País, 1 de octubre de 2015, en http://internacional.elpais.com/internacional/2015/09/30/actualidad/1443599626_907354.html

${ }^{27}$ Chulov, Martin: "Syrian fighting rages as rebels push for Damascus breakthough", The Guardian, 30 November 2012, en https://www.theguardian.com/world/2012/nov/30/syria-rebels-push-for-damascus

${ }^{28}$ Bassam, Laila y Perry, Tom: “'Send Qassem Soleimani': Here's how Putin and Iran plotted out their new assault in Syria, Reuters, 6 October 2015, en https://www.businessinsider.com/r-how-iranian-general-plotted-out-syrianassault-in-moscow-2015-10; Sharafedin, Bozorgmehr: "Iranian commander Soleimani meets Putin in Moscow", Reuters, 16 December 2015, en https://www.reuters.com/article/uk-mideast-crisis-iran-russiaidUKKBNOTZ1NY20151216; "Bashar al-Assad's decade of destruction in Syria”, The Guardian: Today in Focus, 2 June 2021, en https:/www.theguardian.com/news/audio/2021/jun/02/bashar-al-assads-decade-of-destructionin-syria-podcast

${ }^{29}$ Jordán Enamorado, Javier: "La intervención militar de Rusia en Siria: oportunidades y riesgos", Instituto Español de Estudios Estratégicos, Documento marco, $\mathrm{n}^{\mathrm{o}} 27$ (2015), pp. 1-22, p. 10, en http://www.ieee.es/publicaciones-new/documentos-marco/2015/DIEEEM27-2015.html

${ }^{30}$ Katz, Mark N.: "The Russian Approach to Middle East Conflicts and the Arab World", IEMed., Mediterranean Yearbook (2016), pp. 28-32, p. 31, en https://www.iemed.org/observatori/arees-danalisi/arxiusadjunts/anuari/med.2016/IEMed_MedYearBook2016_Russian\%20Approach\%20Middle\%20East_Mark_Katz.p df

${ }^{31}$ Milosevich-Juaristi, Mira: "La finalidad estratégica de Rusia en Siria y las perspectivas de cumplimiento del acuerdo de Astaná”, Real Instituto Elcano, ARI, nº $43 \quad$ (2017), en
} 
rusos que el ejército sirio pudo reconquistar Palmira, la antigua ciudad célebre por sus ruinas de época románica que fueron arrasadas por el Daesh durante su asedio. ${ }^{32}$ Asimismo, Irán fue el primer país en ofrecer y prestar su ayuda al gobierno de Siria, enviando allá algunos de sus consejeros militares y unos 5.000 hombres de su Guardia revolucionaria, el cuerpo de élite del ejército iraní. ${ }^{33}$ Teherán defendió su intervención argumentando que la consolidación en Iraq y en Siria del Daesh y de otras organizaciones terroristas sunníes, como al-Qaeda en Iraq o el HTS, representarían una amenaza grave para la estabilidad de estos Estados y, entonces, un problema apremiante para su seguridad interna. Gracias a la acción conjunta de Rusia e Irán, el régimen de al-Assad, no solo consiguió librarse de la banda terrorista del Daesh, por aquel entonces uno de los grupos de oposición más insidiosos, sino que también ha podido volver a ejercer su control sobre aproximadamente el $60 \%$ del territorio sirio. ${ }^{34}$

Ahora bien, con la progresiva pérdida de control de las áreas ocupadas en Iraq y en Siria, debida a esta dúplice intervención armada, el Daesh empezó a perder también muchas fuentes de financiación, pasando de los 81 millones de dólares mensuales de mitades de 2015, a los 16 millones de dólares, recaudados a mediados de 2017, último año del que disponemos de datos acerca de sus entradas. ${ }^{35} \mathrm{~A}$ falta de un arraigo firme en el territorio, todos los beneficios directamente relacionados con el dominio territorial, como la extorsión, los secuestros de personas, la confiscación de bienes, la reintroducción de una antigua tasa impuesta a los no musulmanes (la jizya), el contrabando de droga, armas y antigüedades, o la extracción y venta de crudo, se vieron gravemente afectadas. Desde este punto de vista, la pérdida de la ciudad iraquí de Mosul, así como de las ciudades sirias de Raqqa y Homs, supusieron un retroceso grave para las ambiciones de conquista global del Daesh. ${ }^{36}$ Con la caída en 2019 de Baghuz, un pueblo sirio fronterizo a orillas del rio Éufrates, el grupo terrorista perdía su última posesión, alrededor de 12.000 de sus miembros caían prisioneros de las FDS y más de 60.000 familiares de terroristas del Daesh acababan en campos para desplazados internos. ${ }^{37}$ Se sancionaba así el fracaso de su proyecto de crear un "Estado islámico", ${ }^{38}$ si bien la banda siga operando mediante actividades de insurgencias y acciones terroristas, tanto en Iraq como en Siria. ${ }^{39}$

http://www.realinstitutoelcano.org/wps/portal/rielcano_es/contenido?WCM_GLOBAL_CONTEXT=/elcano/elca no_es/zonas_es/mediterraneo+y+mundo+arabe/ari43-2017-milosevichjuaristi-finalidad-estrategica-rusia-siriaacuerdo-astana

${ }^{32}$ Sancha, Natalia: "El Ejército sirio, a las puertas de Palmira en una ofensiva contra el ISIS", El País, 25 de marzo de 2016, en

https://internacional.elpais.com/internacional/2016/03/24/actualidad/1458838150_524705.html

${ }^{33}$ Milosevich-Juaristi, op. cit., p. 3.

34 "Syria's Assad set for election win 10 years after start of war", France24, 9 March 2021, en https://www.france24.com/en/live-news/20210309-syria-s-assad-set-for-election-win-10-years-after-start-of-war 35 "Islamic State Territory Down 60 Percent and Revenue Down 80 Percent on Caliphate's Third Anniversary, IHS Markit Says", Conflict Monitor by IHS Markit, 29 June 2017, en http://news.ihsmarkit.com/pressrelease/aerospace-defense-security/islamic-state-territory-down-60-percent-and-revenue-down-80

36 Bonet, Ethel: "El Estado Islámico pierde su feudo en Irak", La Razón, 10 de julio de 2017, en http://www.larazon.es/internacional/el-primer-ministro-iraqui-declara-la-victoria-en-mosul-tras-vencer-a-daesh-

AE15551625; Muir, Jim: “Islamic State': Raqqa's loss seals rapid rise and fall”, BBC News, 17 de octubre de 2017, en https://www.bbc.com/news/world-middle-east-35695648

37 "Syria Conflict Overview: 2011-2021", Congressional Research Service, 10 February 2021, en https://crsreports.congress.gov/product/pdf/IF/IF11080

${ }^{38}$ Reinares, Fernando: “A menos Estado Islámico, más al-Qaeda”, Real Instituto Elcano, Blog Elcano, 28 de marzo de 2019, en https://blog.realinstitutoelcano.org/a-menos-estado-islamico-mas-al-qaeda/

${ }^{39}$ Zelin, Aaron y Knights, Michael: "The Islamic State's Resurgence in the COVID Era? From Defeat to Renewal in Iraq and Syria", The Washington Institute for Near East Policy, 29 May 2020, en https://www.washingtoninstitute.org/policy-analysis/islamic-states-resurgence-covid-era-defeat-renewal-iraqand-syria 


\section{3. ¿Y ahora que Daesh ha sido derrotado sobre el terreno y al-Assad sigue en su lugar?}

En la actualidad, tanto la operación Determinación absoluta, como la campaña aérea de Rusia, respaldada sobre el terreno por Irán, siguen desarrollándose en el territorio sirio. Sin embargo, como indicamos, el Daesh, al menos por lo que afecta a Siria, fue vencido sobre el terreno hace ya dos años. Es legítimo, por tanto, preguntarse por qué hay todavía más de 80 Estados que siguen participando - directa e indirectamente, militar o logísticamente - en la guerra contra el Daesh en el marco de esta operación. ${ }^{40}$ Como el lector puede imaginarse, no profundizaremos en estas pocas páginas en las razones geoestratégicas que mueven a todos los países involucrados en la lucha contra la banda terrorista. Nos centraremos, por tanto, en los que consideramos ser los protagonistas principales de este capítulo de las relaciones internacionales a lo largo ya de diez años. En particular, daremos cuenta de las posturas de las principales potencias regionales involucradas en el conflicto sirio, esto es, Arabia Saudí, Turquía e Irán, que irrumpieron en ello para combatir a los yihadistas del Daesh, pero, al mismo tiempo, con objetivos nacionales e internacionales diferentes. Por otro lado, analizaremos las motivaciones que empujan a las mayores potencias globales que intervienen en Siria, los Estados Unidos y Rusia, a seguir ahí después de haber ganado al Daesh, razón oficial de su involucración en la guerra civil siria.

Salta inmediatamente a la vista la amplia participación que ha conseguido la operación Determinación absoluta, así como la variedad de los países que participan en ella. Estas circunstancias implican que a la diversidad de los Estados partícipes se suma la pluralidad de los objetivos que cada Estado persigue con su participación. En efecto, si antes de la caída del Daesh se podía hablar de unos objetivos diferentes, pero convergentes a la vez, ahora, con la capitulación del grupo terrorista, se ha hecho aún más difícil encontrar un fin común para los Estados intervinientes. En esta tesitura, en la que se mezclan distintos y opuestos intereses geopolíticos que hacen imprevisibles los derroteros que tomará el conflicto sirio, conviene profundizar en los objetivos de las potencias regionales e internacionales involucradas en Siria, Estado y campo de batalla crucial en atención a su posición geográfica, en el corazón de una región de mayoría sunní. ${ }^{41}$

\subsection{Las motivaciones de la participación de algunas potencias de la región: los casos de Arabia Saudí, Turquía e Irán}

En primer lugar, se analizará la posición - aparentemente paradójica - de Arabia Saudí en el conflicto, ya que, desde el comienzo de la guerra civil siria, con su participación en la operación Determinación absoluta, la monarquía saudita ha abierto un nuevo frente de su perenne guerra subsidiaria (proxy war) con Irán para la hegemonía religiosa, política y militar en Oriente Próximo. ${ }^{42}$ Posición paradójica porque, Arabia Saudí, país ampliamente sunní de la rama wahabita, comparte la doctrina que imbuye algunas organizaciones yihadistas que combaten en Siria, entre las cuales el mismo Daesh, cuyos milicianos utilizaban libros religiosos saudíes para propagar la intolerancia y el odio contra los infieles, ${ }^{43}$ y que ahora Riad persigue para defender a los musulmanes sunníes de Siria. No obstante, se ha dicho que la actitud de Riad es solo aparentemente paradójica. En efecto, Arabia Saudí tiene preocupaciones que van más allá que la sola secularización de la sociedad siria, emprendida con Hafez al-Assad y seguida con su

\footnotetext{
${ }^{40}$ Para más información sobre la operación Determinación absoluta se puede visitar la página web de la operación misma: https://www.inherentresolve.mil/

${ }^{41}$ Abhyankar, Rajendra M. (2020): Syria: The Tragedy of a Pivotal State, Singapore, Palgrave Macmillan, p. 116.

42 Priego Moreno, Alberto: "La nueva política exterior de Arabia Saudî”, Instituto Español de Estudios Estratégicos, Documento marco, $\mathrm{n}^{\mathrm{o}} 18$ (2015), pp. 1-20, p. 15, en http://www.ieee.es/Galerias/fichero/docs_marco/2015/DIEEEM182015_NuevaPoliticaExterior_ArabiaSaudi_A.Priego.pdf

${ }^{43}$ McMaster H.R. (2020): Battlegrounds. The Fight to Defend the Free World., London, William Collins, p. 282.
} 
hijo Bashar, teniendo también inquietudes más prosaicas que le obligan a tomar parte activa en el asunto sirio para atenuar el peso iraní en Siria. ${ }^{44}$ Ante todo, la presencia de una organización terrorista como la del Daesh que pretendía crear un Estado islámico global, representa en sí misma una amenaza para la dinastía de los al-Saud, apuntados como apóstatas por la propaganda del grupo terrorista. ${ }^{45}$ De hecho, las miras expansionistas sin fronteras del Daesh convirtieron también a Arabia Saudita - a pesar de su afinidad ideológica con el califato - en blanco de las acciones terroristas de la banda, como las que realizaron en el verano de 2016 en Medina, ciudad que hospeda los restos mortales del mismísimo profeta Mahoma. ${ }^{46}$

No obstante, es preciso señalar que la participación de Arabia Saudita en la coalición anti-Daesh, desde el punto de vista militar, ha sido insignificante, reduciendo el valor de Arabia Saudita como socio militar para los Estados Unidos. ${ }^{47}$ Desde esta perspectiva, una vez que fue más evidente que al-Assad iba a mantener las riendas del poder, el entusiasmo de Riad acerca de una posible eliminación del régimen chií alauí sirio (que constituye para Irán el punto de contacto para armar y financiar a la organización terrorista chií Hezbollah en el Líbano), disminuyó. ${ }^{48}$ Tanto es así que en tiempos recientes se han dado algunas señales que inducen a pensar en una primera, tímida, reconciliación entre Riad y Damasco. Al igual que sus aliados en Egipto y en los Emiratos Árabes Unidos, Arabia Saudí teme tanto la expansión turca como la de los Hermanos Musulmanes, por lo que parece estar planteándose la posibilidad de aproximarse al gobierno sirio. Desde esta perspectiva, se entiende su aprobación de la reapertura, en 2018, de la Embajada de Bahréin en Siria lo que, en su día, dejaba presagiar que Riad hubiera hecho lo mismo. Igualmente, durante 2020, consintió la entrada y el paso de camiones sirios, cargados de mercancías con destino el reino saudita; un cambio significativo si pensamos a las restricciones impuestas en esta década de conflicto, lo que sugiere un posible deshielo en las relaciones entre ambos países. Una sensación que sale reforzada de las palabras expresadas por los ministros de Asuntos Exteriores de Rusia y Arabia Saudí, cuando durante una rueda de prensa mencionaron la posibilidad de un regreso de Siria dentro de la "familia árabe", ${ }^{49}$ con referencia a su posible readmisión en la Liga Árabe después de suspender su membresía, pronunciarse a favor de las fuerzas rebeldes, admitir el derecho de los Estados a ofrecer su ayuda (incluso militar) para proteger la población siria y asistir el Ejército Nacional Sirio (el antiguo Ejército Libre Sirio) e imponerle unas sanciones económicas y políticas. ${ }^{50}$

\footnotetext{
${ }^{44}$ Prieto Arellano, Fernando: "Choque de trenes en el mundo islámico. Repercusiones geoestratégicas de la ruptura de relaciones entre Arabia Saudí e Irán”, Instituto Español de Estudios Estratégicos, Documento de opinión, nº 28 (2016), pp. 1-17, p. 2, en http://www.ieee.es/Galerias/fichero/docs_opinion/2016/DIEEEO28-

2016_ChoqueTrenes_MundoIslamico_ArabiaSaudi_PrietoArellano.pdf

${ }^{45}$ Poza Cano, David: "El derrumbe del 'statu quo' en Oriente Próximo: las estrategias de seguridad de Irán y Arabia Saudî”, Instituto Español de Estudios Estratégicos, Documento de opinión, no 10 (2017), pp. 1-16, p. 9, en http://www.ieee.es/Galerias/fichero/docs_opinion/2017/DIEEEO10-2017_OrienteProximo_DavidPoza.pdf

${ }^{46}$ Carrión, Francisco: "Tres ataques suicidas contra mezquitas y un consulado en Arabia Saudí en 24 horas", El Mundo, 4 de julio de 2016, en http://www.elmundo.es/internacional/2016/07/04/577a948fe5fdea4e148b4645.html

${ }^{47}$ Carter Ash (2019): Inside the Five-Sided Box, New York, Penguin, pp. 295-297

${ }^{48}$ Cafiero, Giorgio y Wagner, Daniel: "Saudi Arabia's Dark Role in the Syria Conflict", The Huffington Post, 6 de julio de 2013, en http://www.huffingtonpost.com/daniel-wagner/saudi-arabias-dark-role-i_b_3402447.html

49 Shabbir, Fahad: "Riyadh Reaffirms Support For Syrian Settlement In Interests Of 'Brotherly' Nation", Urdupoint, 10 de marzo de 2021, en https://www.urdupoint.com/en/world/riyadh-reaffirms-support-for-syriansettlemen-1190115.html

${ }^{50}$ Samir, Ayman y Saleh, Yasmine: “Arab League clears member states to arm Syria rebels", Reuters, 6 de marzo de 2013, en http://www.reuters.com/article/us-syria-crisis-league-lebanon-idUSBRE92517F20130306; Tesón, Nuria: "La Liga Árabe suspende a Siria y le impone sanciones", El País, 12 de noviembre de 2011, en https://elpais.com/internacional/2011/11/12/actualidad/1321109380_030047.html
} 
Como explica el profesor Rajendra Abhyankar, los adversarios árabes de al-Assad sufren un dilema geopolítico contraintuitivo en este caso, porque al haber fracasado en su intento de cortar el lazo que une Siria con Irán a través del medio militar, armando a los opositores sirios del régimen, ahora se encuentran en la necesidad de crear vínculos económicos con Siria para evitar que este se convierta en un Estado completamente subyugado a Teherán. Desde este punto de vista, se puede entender la pretensión de los Estados del Golfo Arábigo de volver a abrir las actividades comerciales con Siria y el flujo de dinero derivado de los numerosos proyectos de reconstrucción del país, ya que "Gulf investors and companies are equally eager to get a slice of the rebuilding pie". ${ }^{51}$ A este respecto, no se puede ignorar el obstáculo que representa el régimen de sanciones que los Estados Unidos impusieron contra Siria y que castiga a cualquier empresa o individuo que trate con los sirios sancionados. Así, por ejemplo, al pedir el regreso de Siria en la Liga Árabe, los Emiratos Árabes Unidos confirmaron que estas sanciones obstaculizan la posible reincorporación de Siria. Todo depende de la diligencia que la administración Biden pondrá en hacer respetar estas medidas de la anterior presidencia Trump (aunque estas medidas nacieran por iniciativa del Congreso y no de la Casa Blanca).

Pese a estas aperturas parciales en favor de Damasco, Arabia Saudí sigue manteniéndose cautelosa, ya que recela de la creciente presencia iraní en territorio sirio, si bien la reconciliación con al-Assad podría permitirle diluir un poco el papel de Irán, su presencia seguiría siendo solo marginal e, incluso, podría acabar recompensando a su rival. ${ }^{52}$

Quedándonos siempre en la región de Oriente Próximo, pero moviéndonos decididamente hacia el Norte, veamos ahora cuál es, después de casi diez años de involucración en conflicto sirio, la posición actual de Turquía. La razón oficial que empujó inicialmente al gobierno de Erdoğan a sumarse a la operación Determinación absoluta, fue la avanzada amenazadora de los terroristas del Daesh hacia la extensa frontera de más de mil kilómetros que Turquía comparte con Siria e Iraq. ${ }^{53}$ después de una actitud, como mínimo, negligente y complaciente respecto al fenómeno del "turismo yihadista del terror" ${ }^{54}$ hacia Siria e Iraq de los terroristas combatientes extranjeros, ${ }^{55}$ Pero Turquía ante los acontecimientos y el nuevo papel de los kurdos en Siria decidió finalmente, reformular su estrategia. El 15 de julio de 2015 se rompieron las conversaciones de paz que mantenía Turquía con el PKK, el asunto del partido nacionalista kurdo del norte de Siria (el Partido de Unión Democrática o PYD), aliado del PKK turco que tiene su brazo armado en las Fuerzas Democráticas Sirias, entre las cuales destacan las YPG y sus apoyos cobraron más importancia, dado su implantación en la zona fronteriza de

\footnotetext{
${ }^{51}$ Abhyankar, op. cit., p. 91.

${ }^{52}$ Phillips, Christopher, "Syria war: Will the Arab League welcome back Assad", Middle East Eye, 15 de marzo de 2021, en https://www.middleeasteye.net/opinion/syria-war-assad-arab-league-welcome-back-will

${ }^{53}$ Altunişik, Meliha Benli: "Turkey in 2014: Juggling Domestic and Foreign Policy Challenges", IEMed.,

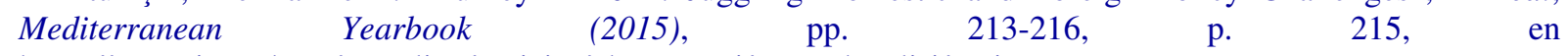
https://www.iemed.org/actualitat/noticies/observatori/arees-danalisi/arxiusadjunts/anuari/med.2015/IEMed\%20Yearbook\%202015_Panorama_Turkey_MelihaBenliAltunisik.pdf

${ }^{54}$ Ambos, Kai: "Our terrorists, your terrorists? The United Nations Security Council urges states to combat 'foreign terrorist fighters', but does not define 'terrorism'”, EJIL: Talk!, 2 de octubre de 2014, en http://www.ejiltalk.org/our-terrorists-your-terrorists-the-united-nations-security-council-urges-states-to-combatforeign-terrorist-fighters-but-does-not-define-terrorism/

${ }^{55}$ Cagaptay, Soner y Yolbulan, Cem: “Turkey at a Crossroads", IEMed., Mediterranean Yearbook (2016), pp. 5156 , p. 55, en

https://www.iemed.org/observatori/arees-danalisi/arxiusadjunts/anuari/med.2016/IEMed_MedYearBook2016_Turkey\%20at\%20a\%20Crossroad_Cagapatay_Yalbulan.p df; Martín Rodríguez, op. cit., p. 93.
} 
Siria. Las prioridades y políticas de los Estados Unidos y Turquía fueron ya divergentes ${ }^{56}$. Para Turquía, el asunto prioritario era la amenaza del YPG, no el derrocamiento de al-Assad.

Así, el 24 de julio lanzó una campaña contra el Partido de los Trabajadores del Kurdistán turco (PKK) en el norte de Iraq y contra el Daesh en Siria para asegurar una zona en la parte norte de Siria de 68 millas de largo y 40 millas de ancho en territorio sirio al este del Éufrates -zona controlada por el Daesh-, previo acuerdo con la administración Obama, pero no se aceptó crear una zona de exclusión aérea.

En la reunión del Consejo Atlántico del 28 julio a petición de Turquía, se manifestó la solidaridad con Ankara y se acordó el apoyo en esta lucha, pero no se dio luz verde a que Turquía luchara contra los kurdos de las Unidades de Protección Popular (YPG), aliados de los Estados Unidos en Siria en las operaciones terrestres.

Desde septiembre de 2015, Turquía comenzó a permitir a las fuerzas estadounidenses usar dos de sus bases aéreas para bombardear algunos baluartes del Daesh en Siria y en Iraq. Pese a su plan originario de perjudicar cuanto más posible al régimen chií de al-Assad, el cambio fue motivado, como indicamos, por el temor a las implicaciones del reforzamiento del YPG y, en otro orden, por la llegada masiva de refugiados sirios (hoy en día son todavía más de 3.600.000 $)^{57}$ que huían de las milicias de la banda terrorista, como por una serie de acciones suicidas perpetradas por los terroristas del Daesh en suelo turco, causando la muerte de centenares de personas, entre los cuales numerosos jóvenes manifestantes pacíficos. ${ }^{58}$

A la participación de Ankara en la operación Determinación absoluta en función antiDaesh y en apoyo de las multitudes de grupos de oposición reunidos en el Ejército Nacional Sirio en el noroeste de Siria, se sobrepuso y entremezcló la lucha que Turquía empezó a llevar a cabo contra las milicias kurdas del partido nacionalista kurdo del norte de Siria.

La cuestión crucial era que, en 2013, el PYD había anunciado la creación de un Kurdistán sirio en la región autónoma siria de Rojava y había conseguido cierta legitimación internacional, ${ }^{59}$ empezando a contar las fuerzas del YPG con el respaldo militar norteamericano, al ser, junto con los Peshmerga del Kurdistán iraquí, las fuerzas sobre el terreno de referencia para los Estados Unidos en su combate contra el Daesh. En efecto, fueron estas fuerzas las que, a finales de 2014, consiguieron una sucesión de éxitos militares esenciales para derrocar al Daesh, como fue la liberación de millares de yazidíes (miembros de una comunidad de origen kurdo cuya religión combina principios tomados del zoroastrismo, cristianismo e islamismo), ${ }^{60}$ sitiados por los terroristas en la ciudad iraquí de Sinjar y obligados

\footnotetext{
${ }^{56}$ Cagaptay, Soner: "Erdoğan's 'Mini Empire' in Libya and Syria”, Turkeyscope, vol. 4, no 3 (January-February 2020), pp. 1-7, en https://www.washingtoninstitute.org/media/726

${ }^{57}$ Con base en las estimaciones de la Agencia de la ONU para los Refugiados (ACNUR), en el momento en que se escribe son, precisamente, 3.671.811 los refugiados sirios registrados por el Gobierno de Turquía. Véase: https://data2.unhcr.org/en/situations/syria/location/113 (Último acceso el 30 de abril de 2021)

${ }^{58}$ Hurtado, Lluís: "Un centenar de muertos durante una marcha por la paz en Ankara", El Mundo, 10 de octubre de 2015, en http://www.elmundo.es/internacional/2015/10/10/5618c38de2704e34728b458c.html; Mourenza, Andrés: "Un ataque contra un centro kurdo en Turquía deja al menos 30 muertos", El País, 21 de julio de 2015, en https://internacional.elpais.com/internacional/2015/07/20/actualidad/1437388937_401512.html

59 Özel, Isik: "Surrounded by trouble, hit by conflict: Turkey and its manifold challenges", Real Instituto Elcano, ARI, n 4/2016, 18 de enero de 2016, en http://www.realinstitutoelcano.org/wps/portal/rielcano_en/contenido?WCM_GLOBAL_CONTEXT=/elcano/elc ano_es/zonas_es/mediterraneo+y+mundo+arabe/ari4-2016-ozel-surrounded-by-trouble-hit-by-conflict-turkeymanifold-challenges

${ }^{60}$ Jalabi, Raya: "Who are the Yazidies and why is Isis hunting them?", The Guardian, 11 August 2014, en http://www.theguardian.com/world/2014/aug/07/who-yazidi-isis-iraq-religion-ethnicity-mountains
} 
a buscar refugio en las alturas del homónimo monte; ${ }^{61}$ o en el asedio de la ciudad sirio-kurda de Kobane, en la frontera con Turquía, símbolo de la resistencia kurda contra el yihadismo del Daesh. ${ }^{62}$

Por ello, la administración Obama tuvo muy serias fricciones con Turquía que se oponía a estos apoyos al YPG, pero que mantenía la frontera del sur abierta con el territorio controlado por el Daesh con suculentos negocios y suministros. Cuando el 15 de julio de 2015 se rompieron las conversaciones de paz que mantenía Turquía con el PKK, el asunto del YPG y sus apoyos cobró más importancia, dado su implantación en la zona fronteriza de Siria. Las prioridades y políticas de los Estados Unidos y Turquía fueron ya divergentes ${ }^{63}$. Para Turquía, el asunto prioritario era la amenaza del YPG, no el derrocamiento de al-Assad.

Luego, el 24 de noviembre, Turquía derribó un avión Sukoi ruso (Su24) por haber violado su espacio aéreo entrando desde Siria. Como consecuencia, Rusia tomó serias medidas de retorsión contra Turquía, desplegó su flota en el Mediterráneo y denunció, en una rueda de prensa internacional ad hoc realizada en el Ministerio ruso de Defensa, el contrabando de petróleo que Turquía realizaba por tres rutas diferentes desde territorio que controlaba el Daesh en Siria y que, según Moscú, incluía como beneficiarios al presidente Erdoğan y su familia ${ }^{64}$. Contrabando que curiosamente negó el portavoz del Pentágono, Steve Warren. A su vez, el Kremlin amenazó con intervenir en contra de las operaciones militares de Turquía. Erdoğan se defendió negando la implicación suya o de su familia y diciendo que el derribo del avión había sido promovido por sus enemigos políticos y pidió ayuda a la OTAN que acabó instalando en su territorio varios sistemas de defensa antimisil, entre ellos un batería de misiles Patriot española. Pero, aparentemente, el líder turco no quedó del todo satisfecho con el apoyo recibido.

Meses después, el 15-16 de julio tuvo lugar un extraño intento de Golpe de Estado en Turquía que supuso un acercamiento a Rusia mediante continuas y mutuas concesiones, y que permitirá la intervención de Turquía en su frontera sur para impedir que los kurdos controlen el territorio fronterizo con Turquía. Así, una nueva ofensiva, la operación Escudo del Éufrates, se inició el 26 de agosto de 2016 en dirección a al-Bab, justificándola en virtud del artículo 51 de la Carta de Naciones Unidas, y acabando por estructurar una zona tapón que impidiese la unión entre territorios controlados por los kurdos en el este y el oeste de la zona norte de Siria. ${ }^{65}$

Sucesivamente, el 28 de diciembre de 2016, se llegó a un acuerdo de alto el fuego entre Turquía y Rusia, al margen de los Estados Unidos, así como del Daesh, al-Nusra y el YPG que también fueron excluidos del alto el fuego. Y el 4 de mayo de 2017, Rusia, Irán y Turquía firmaron otro acuerdo, esta vez en Astana, para crear cuatro zonas de desescalada, con la construcción de puestos de observación para hacer un seguimiento de dicha desescalada (con la garantía de los tres países). Este acuerdo, que entró en vigor el 5 de mayo de 2017, significaba el inicio de un proceso, los acuerdos de Astana, ${ }^{66}$ que suponían la exclusión de Estados Unidos y el abandono del proceso de Ginebra de las Naciones Unidas. Washington no consideró

\footnotetext{
61 "Yazidíes, la minoría religiosa cercada en una montaña de Irak", BBC Mundo, 7 de agosto de 2014, en https://www.bbc.com/mundo/noticias/2014/08/140807_irak_yazidies_estado_islamico_jp

62 "Los kurdos se alzan en Turquía contra la pasividad del Gobierno al avance de los yihadistas en Kobane", El Mundo, 8 de octubre de 2014, en http://www.elmundo.es/internacional/2014/10/07/54343b64ca474129368b456b.html

${ }^{63}$ Cagaptay, Soner: "Erdoğan's 'Mini Empire' in Libya and Syria", Turkeyscope, vol. 4, no 3 (January-February 2020), pp. 1-7, en https://www.washingtoninstitute.org/media/726

${ }^{64}$ Tsvetkova, Maria y Kelly, Lidia: "Russia presents proof of Turkey's role in ISIS oil trade”, Reuters, 2 December 2015, en https://www.reuters.com/article/us-mideast-crisis-russia-turkey-idUSKBNOTL19S20151202.

${ }^{65}$ Ülgen, Sinan y Kasapoğlu Can: "Operation Euphrates Shield: Aims and Gains”, Carnegie Europe, 19 January 2017, en https://carnegieeurope.eu/2017/01/19/operation-euphrates-shield-aims-and-gains-pub-67754

${ }^{66}$ Memorandum on the creation of de-escalation areas in the Syrian Arab Republic, 6 May 2017, en https://www.mid.ru/en/foreign_policy/news/-/asset_publisher/cKNonkJE02Bw/content/id/2746041
} 
aceptable este acercamiento tan estrecho a Rusia, el principal apoyo de Irán, pero las continuas promesas de retirada, tanto del presidente Obama como del presidente Trump, ya habían creado este caldo de cultivo. ${ }^{67}$

Por su parte, el YPG y otras fuerzas, con el visto bueno estadounidense, avanzaron y atravesaron el Éufrates, impidiendo el avance de Turquía en dirección suroeste. Turquía, en enero de 2017, se había aventurado en una nueva campaña militar, la operación Rama de Olivo, ${ }^{68}$ para tomar el control de la zona que previamente dominaban los kurdos en Afrin.

Figura 2. Operaciones militares de Turquía en Siria (2016-2017)

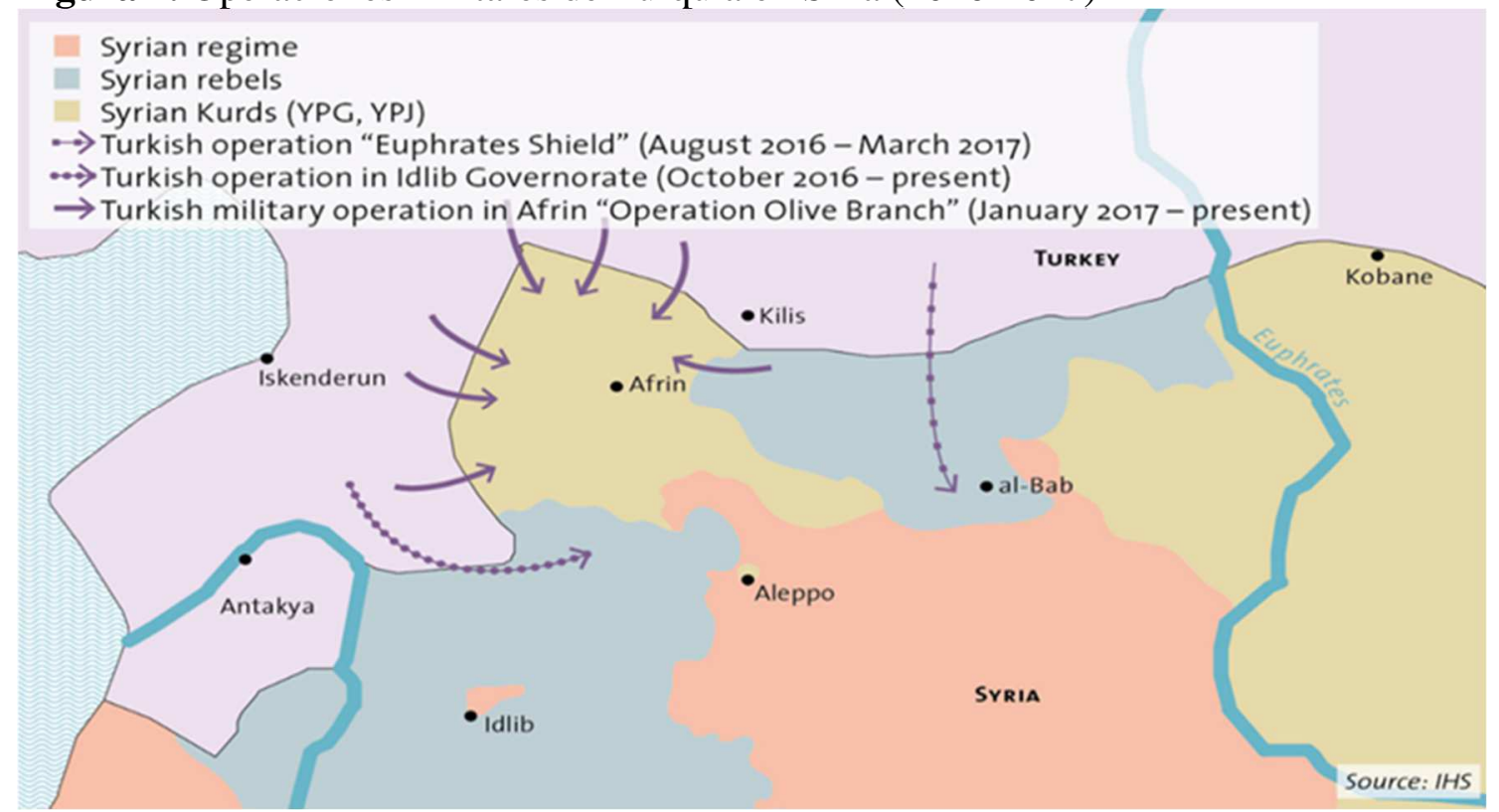

Fuente: JHS

Con la Administración de Trump, Turquía pretendió involucrase en la conquista de la capital del califato, Raqqa, pero la Casa Blanca prefirió seguir contando con el YPG y otros grupos rebeldes. Tanto es así que, a mediados de 2017, los Estados Unidos comenzaron a proporcionar diverso tipo de armamento a las milicias kurdas implicadas en la reconquista de Raqqa ${ }^{69} \mathrm{La}$ distribución de armas entre los kurdos agitó de nuevo bastante a Ankara, creando otra situación un tanto paradójica en torno a la guerra civil de Siria. Turquía persigue al YPG que, a su vez, combate a los terroristas del Daesh gracias al apoyo de los Estados Unidos, aliados también de Turquía en la campaña Determinación absoluta contra esta organización yihadista y en la OTAN. ${ }^{70}$ Posteriormente, el 6 de octubre de 2019, el presidente Trump ordenó replegar las tropas estadounidenses del nordeste de Siria y, con el visto bueno de Washington y Moscú, Turquía realizó, con el apoyo del Ejército Nacional Sirio y sus aliados, la tercera operación, Manantial de paz, ${ }^{71}$ esta vez en el nordeste de Siria.

\footnotetext{
${ }^{67}$ McMaster, op. cit. pp. 268-272.

${ }^{68}$ Ülgen, Sinan y Kasapoğlu Can: “Operation Olive Branch:A Political - Military Assessment”, EDAM, January 2018, n' 2018/2, en https://edam.org.tr/wp-content/uploads/2018/01/Operation-Olive-Branch-01.pdf

${ }^{69}$ Mourenza, Andrés: "Turquía cree inaceptable que EE. UU. arme a las milicias kurdas de Siria", El País, 10 de mayo de 2017, en https://elpais.com/internacional/2017/05/10/actualidad/1494417841_354989.html

${ }^{70}$ Reinares, Fernando: "Turquía y la amenaza terrorista del Estado Islámico", Real Instituto Elcano, Comentario Elcano, $\mathrm{n}^{\mathrm{o}}$ 56/2015, 22 de octubre de 2015, en

http://www.realinstitutoelcano.org/wps/portal/rielcano_es/contenido?WCM_GLOBAL_CONTEXT=/elcano/elca no_es/zonas_es/comentario-reinares-turquia-y-la-amenaza-terrorista-del-autodenominado-estado-islamico

${ }^{71}$ Cebul, Matthew: “Operation 'Peace Spring' and U.S. Strategy in Syria”, Foreign Policy Research Institute, 11 October 2019, en https://www.fpri.org/article/2019/10/operation-peace-spring-and-u-s-strategy-in-syria/
} 
De esta manera, comenzó un "tercer acto" en el conflicto sirio, es decir, la invasión turca del noreste de Siria, iniciada, en palabras de Erdoğan, para crear una zona segura (en su proyecto de unos $30 \mathrm{~km}$ de profundidad y casi $500 \mathrm{~km}$ de largo) en la frontera entre los dos países para impedir la entrada en Turquía de combatientes y refugiados kurdos, facilitada regularmente por los habitantes kurdos que residen en el sureste del país, y al mismo tiempo, posibilitar el regreso a Siria de los millones de refugiados sirios en Turquía. ${ }^{72}$ No obstante, la operación Manantial de paz asume más otros rasgos que los de una campaña pensada para llevar la paz por aquellas tierras, fragmentando más aun Siria y provocando que el YPG, sintiéndose abandonado, entrase de nuevo en contacto con Rusia y el gobierno de Siria. ${ }^{73}$

Figura 3. Operación Manantial de Paz y redespliegue ruso y estadounidense

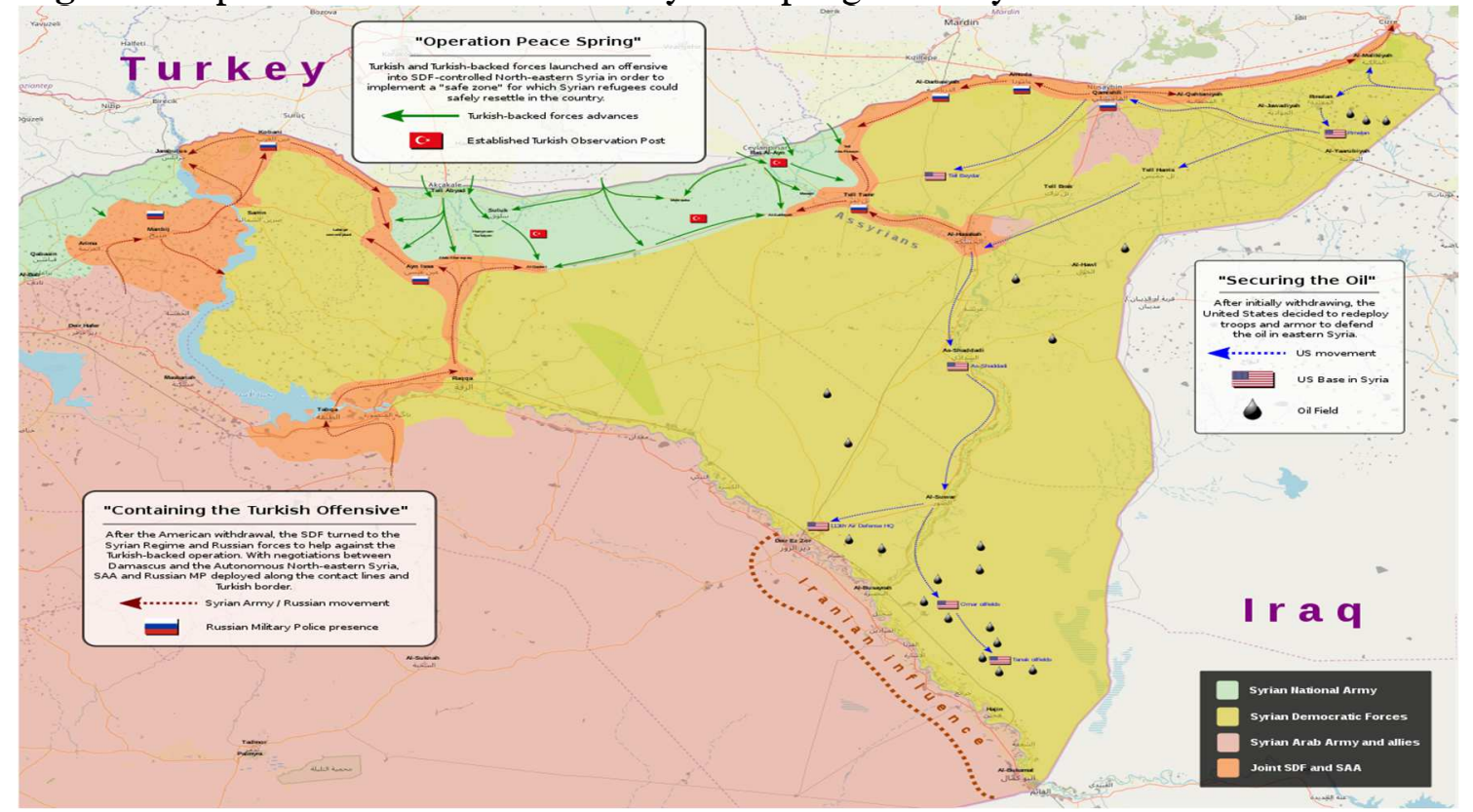

Fuente: Wikipedia

Con la casi completa desaparición del Daesh del mapa de Siria, al-Assad firmemente al mando de su gobierno y el anuncio de retirada de los 2.000 efectivos norteamericanos presentes en Siria por parte del presidente Trump (que no se acabó materializando), ${ }^{74}$ se hizo todavía más patente que, con su participación en la guerra siria, el propósito principal de Erdoğan fue doblegar a las milicias kurdas, percibidas como la amenaza principal a la seguridad y unidad nacional turca, tratando de limitar las posibilidades de una autonomía kurda. En el oeste del país quedaba también otra zona de influencia turca, la zona de Idlib, desarrollándose ahí una dinámica compleja con la conquista por las fuerzas gubernamentales de importantes territorios, entre noviembre de 2019 y marzo de 2020, y nuevas negociaciones entre Rusia y Turquía con la posibilidad de llegar a un intercambio, esto es, conceder una zona de seguridad a Turquía a cambio de la retirada de su apoyo a las fuerzas combatientes en la zona.

\footnotetext{
${ }^{72}$ Arteaga, Félix: "Guerra civil en Siria, tercer acto: la invasión turca”, Real Instituto Elcano, Comentario Elcano,

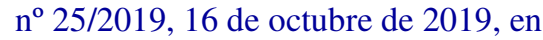

http://www.realinstitutoelcano.org/wps/portal/rielcano_es/contenido?WCM_GLOBAL_CONTEXT=/elcano/elca no_es/zonas_es/comentario-arteaga-guerra-civil-en-siria-tercer-acto-invasion-turca

73 "Russia urges Kurdish fighters to withdraw from Syria's border", Aljazeera, 23 October 2019, en https:/www.aljazeera.com/news/2019/10/23/russia-urges-kurdish-fighters-to-withdraw-from-syrias-border/; "US-backed YPG aligns itself with regime, Russia", Daily Sabah, 15 October 2019, en https://www.dailysabah.com/politics/2019/10/15/us-backed-ypg-aligns-itself-with-regime-russia

${ }^{74}$ International Crisis Group: “After Ten Years of War, Conflict Still Paralyses Syria”, 15 March 2021, en https://www.crisisgroup.org/middle-east-north-africa/eastern-mediterranean/syria/after-ten-years-war-conflictstill-paralyses-syria
} 
Figura 4. Territorios controlados por Turquía en Siria a finales de 2020

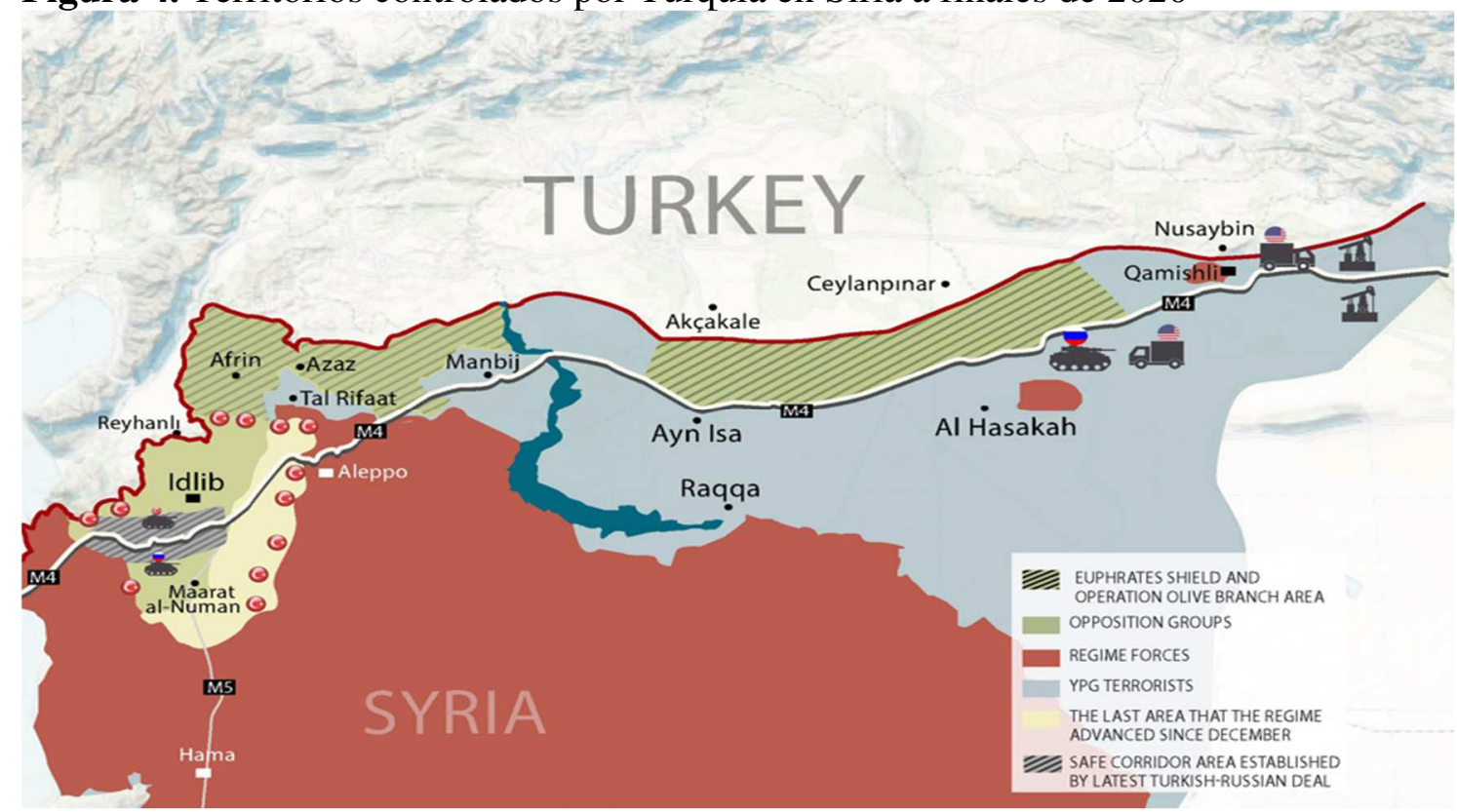

Fuente: Daily Sabah

Por último, al otro bando del tablero sirio, entre las potencias regionales, conviene detenerse brevemente en la postura de Irán que está aprovechándose del conflicto para obtener algunos beneficios en su "Guerra Fría regional" 75 contra Arabia Saudita. Desde el golpe de Estado de 1963, Siria está gobernada por los alauitas, una secta chií que representa el 10-15\% de la población siria mayoritariamente sunní, que maneja las palancas del poder y la estructura de mando del Partido Ba' ath, el partido de los al-Assad. ${ }^{76}$ Por lo que, cuando en 1979, se produjo en Irán la Revolución islámica, Teherán identificó en el régimen sirio un aliado natural para ejercer su influencia en Levante. Sin embargo, las razones históricas y el componente religioso son solo algunos de los elementos que nos permiten comprender las razones que están en la base del apoyo iraní al gobierno sirio. En efecto, pese a que ambos Estados sean de los pocos países guiados por líderes chiitas, los objetivos iraníes en Siria son también muy pragmáticos. No se puede olvidar que Siria, por su posición geográfica, garantiza a Irán un acceso a los movimientos islamistas de Hamas en la Franja de Gaza y de Hezbollah en el Líbano, permitiéndole desplegar su autoridad en el Mediterráneo oriental y reforzar así su poder disuasorio de cara a Israel y a los Estados Unidos. ${ }^{77}$ De hecho, durante esta década de conflicto en Siria, Irán es el país que más decididamente ha apostado por respaldar al gobierno de Damasco. La asistencia de Teherán no se ha traducido solo en el envío masivo de fuerzas y milicias chiitas de diversa procedencia (estimados a partir de 2015 en unos 8.000-10.000 fuerzas ligadas a la Guardia Revolucionaria a lo que hay que añadir entre 5.000 y 6.000 soldados del Ejército regular iraní y otros 8.000 combatientes de Hezbollah) ${ }^{78}$ en el equipamiento y en el entrenamiento del ejército sirio por parte de la Guardia Revolucionaria de Irán, sino también en el apoyo, económico y militar, a Hezbollah que, a su vez, respalda al régimen sirio y es el

\footnotetext{
${ }^{75}$ Abhyankar, op. cit., p. 116.

${ }^{76}$ Ibid., p. 6; Milosevich-Juaristi, op. cit., pp. 2-3.

${ }^{77}$ Djalili, Mohammad-Reza y Kellner, Thierry: "Scramble for Syria", The Cairo Review of Global Affairs, 2017, pp. 1-6, en https://www.thecairoreview.com/wp-content/uploads/2017/07/cr26-kellner.pdf

${ }_{78}^{78}$ Yahel, Ido: "Iran in Syria: From Expansion to Entrenchment", Tel Aviv Notes, vol. 15, no 5, 17 June 2021, en https://dayan.org/content/iran-syria-expansion-entrenchment; Israel Defense Forces: "Iranian Forces Deployed in Syria", en https://www.idf.il/en/minisites/iran/iran-in-syria/iranian-forces-deployed-in-syria/
} 
principal freno iraní contra Israel. ${ }^{79}$ En particular, desde 2012, alrededor de 3.000 oficiales, al mando del fallecido comandante Qassem Soleimani, asumieron el adiestramiento de las numerosas milicias que componen la Fuerza de Defensa Nacional (FDN), cuerpo paramilitar creado por el gobierno sirio para compensar las carencias y las defecciones de su ejército regular, para compactarlas y crear así una entidad homogénea ${ }^{80}$ Por lo que, es fácil entender como el apogeo del Daesh ofreciera a Irán el pretexto perfecto para legitimar internacionalmente su enérgica intervención, directa e indirecta, en Siria en apoyo del régimen. Y no se puede decir que Teherán no haya cumplido con su misión: Bashar al-Assad ha recuperado el control sobre la mayor parte del territorio y las principales ciudades sirias, evitando así la repartición del país entre grupos rivales; ${ }^{81}$ al mismo tiempo, ha conseguido - de momento - disipar la amenaza yihadista salafista que representaba el Daesh. Sin embargo, precisamente la derrota de la organización terrorista nos demuestra, otra vez, que esta nunca ha sido la razón principal de la participación iraní en otra de sus guerras subsidiarias contra Israel y Arabia Saudita y que Teherán no considera que el periodo sucesivo a la derrota del Daesh en Siria represente la fase final del conflicto. ${ }^{82}$ La necesidad de mantener uno de sus más importantes aliados en la región es el objetivo primario de Irán, junto con el apoyo al creciente chiita, conseguir acceso a Latakia en el Mediterráneo por varias posibles vías de acceso (incluido el ferrocarril desde Iraq), así como obtener una mejor posición en su política con Israel y una disuasión avanzada contra Turquía, Arabia Saudita, Israel y los Estados Unidos, tratando que estos últimos se retiren de la región, alcanzando así, finalmente, una hegemonía regional contra Turquía y Arabia Saudita.

Lo demuestran sus esfuerzos para reforzar su presencia en las zonas bajo control de sus aliados - desde el oeste de Iraq, pasando por el sureste de Siria y el Líbano, hasta la costa mediterránea - conocidas también como "media luna chiita" y su construcción de infraestructuras para corredores terrestres, el establecimiento de centros culturales y religiosos y acuerdos económicos de gran amplitud con el gobierno de Siria. ${ }^{83}$ En concreto, las milicias bajo mando iraní están intentando afincarse de manera permanente en el sur de Siria, cerca de la frontera israelí en los Altos del Golán que los acuerdos entre Rusia e Israel han limitado. Israel, por su parte, pese a no querer ser una parte visible en la guerra civil internacionalizada y prefiriendo un "malo conocido que bueno por conocer" 84 - y por eso fuera de esta panorámica general de los intereses geopolíticos de las mayores potencias regionales - no se ha quedado de brazos cruzados contemplando cómo Irán va aumentando su influencia en el área, procediendo

79 Nader, Alireza: "Iran's Goals in Syria", The RAND Blog, 1 January 2015, en https://www.rand.org/blog/2015/01/irans-goals-in-syria.html; Pardo de Santayana Gómez de Olea, José: "Rusia y EEUU en el laberinto de Oriente Próximo", Instituto Español de Estudios Estratégicos, Documento de análisis, $\mathrm{n}^{\circ}$ 28 (2017), pp. 1-15, p. 8, en

http://www.ieee.es/Galerias/fichero/docs_analisis/2017/DIEEEA28-2017_EEUU-Rusia-Laberinto-

OrienteMedio_JMPSGO.pdf

${ }^{80}$ Sancha, Natalia: "La legión extranjera que lucha con El Asad”, El Pais, 7 de enero de 2017, en https://elpais.com/internacional/2017/01/06/actualidad/1483729107_372698.html.

${ }^{81}$ Ansari, Ali y Bassiri Tabrizi, Aniseh: "The View from Tehran”, en Bassiri Tabrizi, Aniseh y Pantucci, Raffaello (eds.) (2016): Understanding Iran's Role in the Syrian Conflict, London, Royal United Services Institute for Defence and Security Studies, pp. 3-11, en particular, p. 7.

${ }^{82}$ Ahmadian, Hassan y Mohseni, Payam: "Iran's Syria strategy: the evolution of deterrence", International Affairs, vol. 95, no 2 (2019), pp. 341-364, p. 363, en

https://academic.oup.com/ia/article/95/2/341/5306386?login=true

${ }^{83}$ Yahel, op.cit.

${ }^{84}$ Dekel, Udi y Valensi, Carmit: “After a Decade of War in Syria, Israel Should Change its Policy”, The Institute for National Security Studies, 7 April 2021, en https://www.inss.org.il/publication/israelassad/?offset $=10 \&$ posts $=3116$ 
al suministro de armas y, en diversas ocasiones, respondiendo a ataques o lanzando ataques aéreos contra infraestructuras militares iraníes en territorio sirio. ${ }^{85}$

Figura 5. Ataques de Israel en 2019

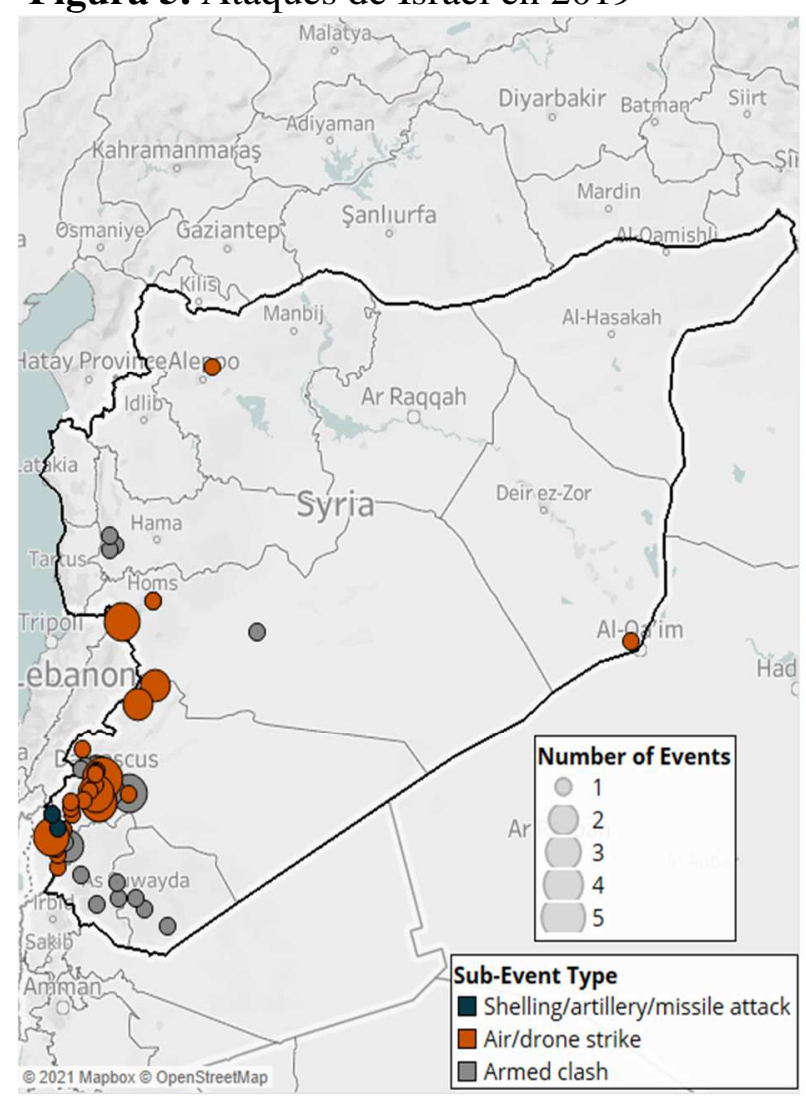

Ataques de Israel en 2020

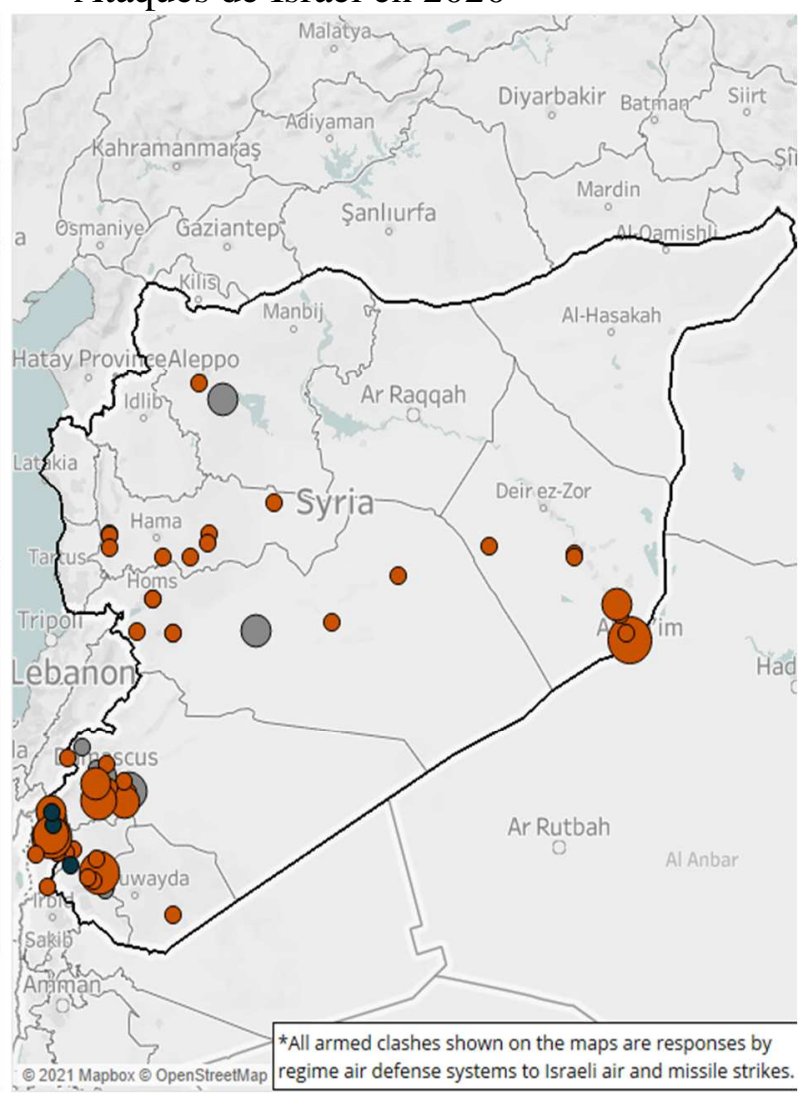

Fuente: ACLED

Del mismo modo, los planes de expansión iraníes en el este sirio se ven perjudicados por la presencia de las Fuerzas Democráticas Sirias que combaten los grupos progubernamentales, apoyados por Irán, y que representan un obstáculo ulterior a los planes de independencia de los kurdos, parte integrante de las FDS. Asimismo, por último, el afán de control que Teherán tiene sobre la frontera entre Siria e Iraq, cuyos destinos Irán considera estrechamente relacionados, y sus tres principales cruces de frontera (el de al-Waleed en el sur en donde convergen las fronteras de Siria, Jordania e Iraq, el de al-Bukamal/al-Qaim, y el de al-Yarubiya/Rabia en el norte), se ve frustrado por la expansión turca en el noroeste de Siria y en el noreste de Iraq y por la presencia militar de los Estados Unidos en al-Tanf. ${ }^{86}$ Pese a estos obstáculos, no hay que dudar que Irán seguirá intentando apuntalar su autoridad en la región, independientemente de cómo acabe la guerra civil siria, en el marco de su estrategia de fortalecimiento del que denomina como el "eje de resistencia". 87

\footnotetext{
${ }^{85}$ Abhyankar, op. cit., pp. 114-115; Ayestaran, Mikel: "Israel bombardea posiciones rebeldes en Siria en el mayor ataque desde 2018", $A B C, 13$ de enero de 2021, en https://www.abc.es/internacional/abci-israel-bombardeaposiciones-rebeldes-siria-mayor-ataque-desde-2018-202101132105_noticia.html; Frantzman, Seth J.: “Israel's Uphill Battle with Iran in Syria", The National Interest, 3 February 2019, en https://nationalinterest.org/feature/israels-uphill-battle-iran-syria-42942

${ }^{86}$ Hasan, Harith y Khaddour, Kheder: "The Transformation of the Iraqi-Syrian Border: From a National to a Regional Frontier", Carnegie Endowment for International Peace, March 2020, pp. 1-29, pp. 16-21, en https://carnegieendowment.org/files/Hasan_Khaddour_Iraq-Syria_Border2.pdf

${ }^{87}$ Abhyankar, op. cit., p. 115.
} 
Figura 6. Pasos fronterizos
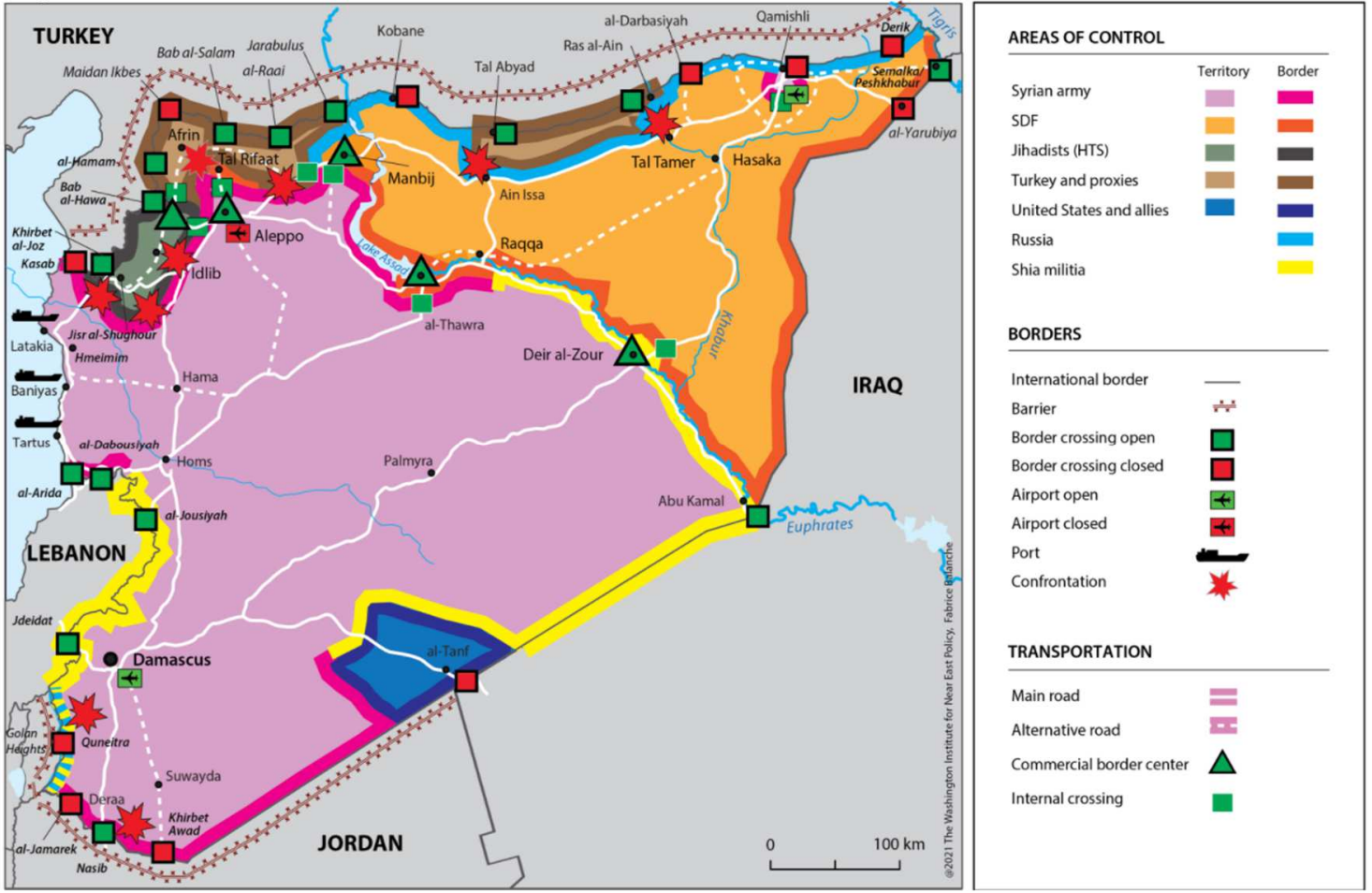

Fuente: The Washington Institute for Near East Policy

Figura 7. Mapa de bases militares e instalaciones extranjeras en Siria (enero 2021)

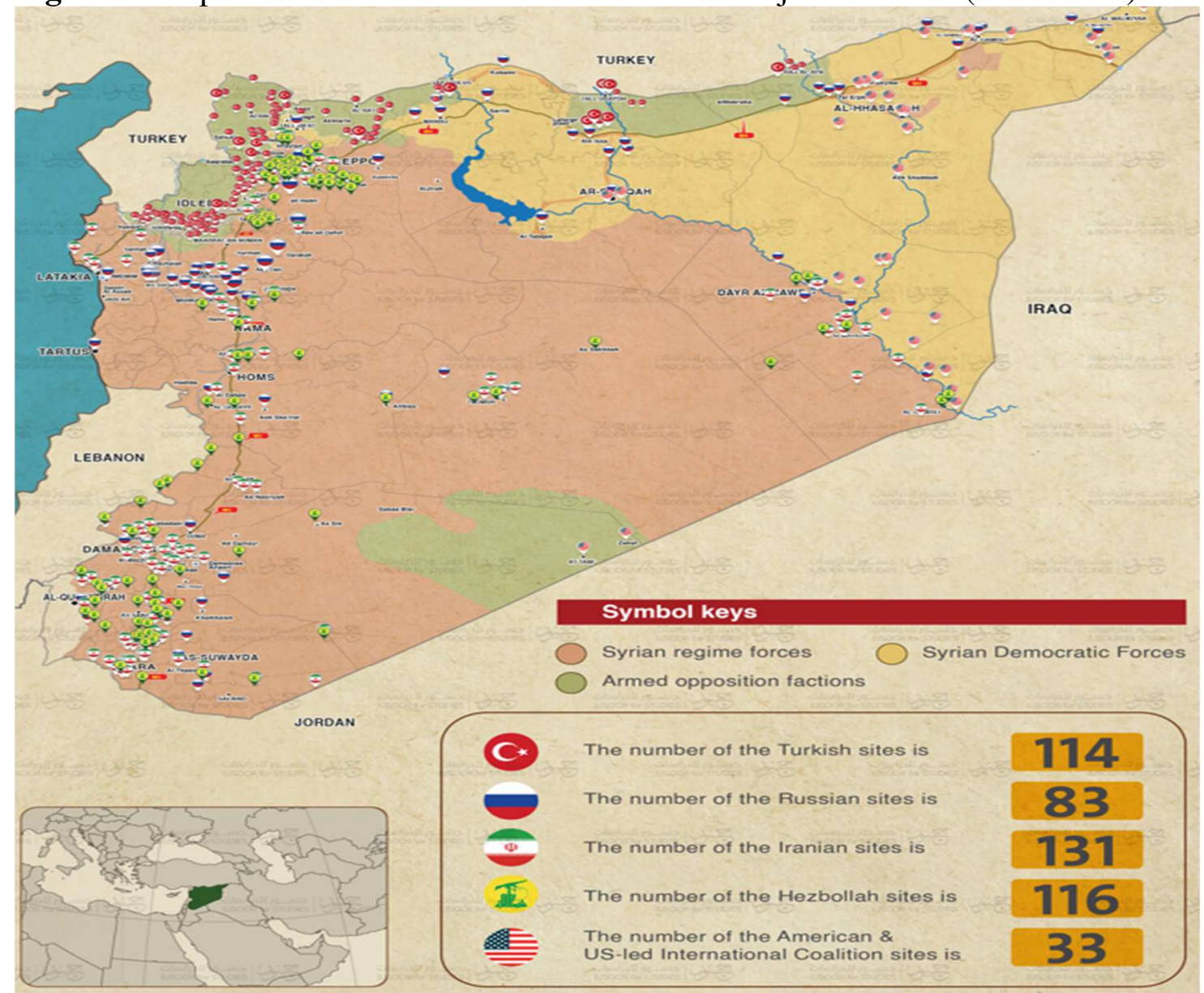

Fuente: Jusoor Center for Studies 


\subsection{Las razones de la intervención de las potencias internacionales: los casos de los Estados Unidos y de Rusia}

El papel jugado por los Estados Unidos en el conflicto sirio desde la Administración Obama ha sido complejo. El presidente demócrata se esforzó para cambiar el enfoque de la política norteamericana en Oriente Próximo, pasando de una orientación fundada en la preponderance a una basada en la llamada offshore balancing, ${ }^{88}$ consistente en una desescalada progresiva de la involucración político-diplomática y del esfuerzo militar de los Estados Unidos en esta región, para que las potencias regionales encontraran su propio equilibrio. ${ }^{89}$ Se explica así la modesta implicación inicial de Washington en la guerra civil siria, ya que no quería empantanarse de nuevo en otro caótico conflicto en Oriente Medio, después de las experiencias desastrosas tenidas con las operaciones Libertad duradera en Afganistán (2001), Libertad iraquí en Iraq (2003) y, en otro orden, Protector unificado en Libia (2011). ${ }^{90}$

Tras el fracaso del plan de la Liga Árabe y la posición de Rusia de que el Consejo de Seguridad tenía que ser más duro con los rebeldes que con el gobierno - a pesar de la durísima represión que estaba teniendo lugar - y de su oposición a toda intervención extranjera, siendo apoyada en ella por China, se asume por la Administración Obama una línea política de cautela, intentando llegar a un compromiso. Así, tras el fracaso del plan de Kofi Annan, Washington decidió apoyar una vía de actuación que implicase una mínima e indirecta intervención en el conflicto, intentando apoyar a la oposición al presidente al-Assad para que le derrocara, pero viviendo en la duda de si estos apoyos podrían poner las bases para una futura insurgencia hostil a los propios Estados Unidos, dada la composición de los grupos rebeldes en 2012, las armas que ya estaban recibiendo de Irán, Turquía y - aunque de forma descoordinada - de algunos Estados del Golfo pérsico, como Arabia Saudita y Catar, y la implicación de fuerzas iraníes y de Hezbollah sobre el terreno. Al final, tras la presentación de un plan por parte del general Petreus, el presidente Obama consideró que era mejor no armar a los rebeldes y firmó una orden secreta autorizando el apoyo financiero y el suministro de equipos no letales, así como el entrenamiento de las fuerzas opositoras, previamente escogidas; selección que creará posteriormente serios problemas, operando como centro de coordinación desde Turquía.

Algunos avances de importancia se realizaron por parte de las fuerzas opositoras en 2012, y el presidente Obama, previendo lo que parecía avecinarse, en agosto de 2012 estableció una línea roja que no se podía traspasar por parte del gobierno de al-Assad: el empleo de armas químicas. No obstante, en marzo de 2013, empezaron a llegar noticias de que el gobierno sirio estaba utilizando armas químicas y la CIA obtuvo el visto bueno para armar a los rebeldes, yendo más allá de canalizar armas, dinero, propaganda y entrenamiento a la oposición como ya venían haciendo, apareciendo estas noticias el 30 de abril de 2013, antes de partir para Moscú John Kerry para discutir con el presidente Putin el tema de Siria y la utilización que ya se estaba haciendo de armas químicas a pequeña escala. ${ }^{91}$ Sucesivamente, en agosto tuvo lugar el ataque del gobierno sirio con armas química en Goutha, traspasando la línea roja que el presidente Obama había establecido, pero que no dio paso a una represalia militar por parte de los Estados Unidos, produciendo una profunda irritación en los aliados árabes y en Turquía. La falta de resolución por parte de la Casa Blanca y su marcha atrás a la hora de adoptar medidas más

\footnotetext{
${ }^{88}$ Acerca de estas nociones, véase, Layne, Christopher: "From Preponderance to Offshore Balancing: America's Future Grand Strategy", International Security, vol. 22, no 1 (1997), pp. 86-124.

${ }^{89}$ Friedman, Brandon: "US Engagement and Disengagement in the Middle East: Paradox and Perception", The Institute for National Security Studies, vol. 24, $\mathrm{n}^{\circ} 1$ (2021), pp. 136-153, pp. 146-148, en https://www.inss.org.il/publication/us-engagement-and-disengagement-in-the-middle-east-paradox-andperception/

${ }^{90}$ Arteaga, Félix: “Obama: leading from behind”, Real Instituto Elcano, Blog Elcano, 13 de septiembre de 2013, en http://www.blog.rielcano.org/obama-leading-from-behind-congress-polls/

${ }^{91}$ Rodham Clinton, Hillary (2014): Hard Choices, New York, Simon \& Shuster, pp. 447-464.
} 
decididas para castigar el uso de armas químicas menoscabó su credibilidad, sacudió la confianza de sus aliados y alentó a los adversarios. ${ }^{92}$ Después del surgimiento del Daesh, los Estados Unidos formaron una coalición para combatirlo militarmente y que implicó su intervención militar directa con bombardeos aéreos. ${ }^{93}$ Sin embargo, el fracaso de los apoyos militares y del entrenamiento a miembros del Ejército Libre Sirio por parte de Washington había sido espectacular, pasándose al Daesh numerosos contingentes. Durante 2015 y 2016 se hicieron progresos importantes y aparecieron importantes tensiones con el gobierno turco por la cooperación que las fuerzas estadounidenses prestaban a los kurdos del YPG y también con el Congreso, donde el senador John McCain criticó la falta de una estrategia real en Siria. Finalmente, en diciembre de 2015 se aprobó un plan para conquistar Raqqa y Mosul. ${ }^{94}$

Con el cambio de presidencia, en enero de 2017, la estrategia norteamericana en Siria siguió encauzada en tres objetivos principales: derrotar al Daesh, detener el uso de armas químicas y contrarrestar la influencia de Irán, compartiendo, tanto los presidentes Obama y Trump, la idea de fondo de que Siria no es una guerra de los Estados Unidos que integre intereses estratégico fundamentales para ellos. ${ }^{95} \mathrm{En}$ consecuencia, la operación siguió limitándose a los bombardeos de los baluartes y de las instalaciones neurálgicas del Daesh, como los pozos petrolíferos, y al apoyo a los rebeldes que Washington consideraba "moderados", entre los cuales los de las Fuerzas Democráticas Sirias, la alianza militar formada por milicias prevalentemente kurdas y árabes, como ya indicamos. De esta forma, consiguieron doblegar a los terroristas del Daesh y pudieron contribuir a su desaparición casi total del territorio sirio. Es más, hubo un momento en el que pareció que la administración Trump quisiera intervenir más decididamente en la guerra, después de que, en abril de 2017, volviesen a utilizarse armas químicas. ${ }^{96}$ El entonces presidente Trump afirmó que, esta vez, al-Assad había "cruzado muchas líneas rojas"97 y autorizó, en represalia, el lanzamiento de 59 misiles de crucero de largo alcance contra la base área siria de Shayrat, al sur de Homs. ${ }^{98}$ Como consecuencia de este nuevo uso de armas químicas, los Estados Unidos volvieron a exigir, después de haber arrinconado la pretensión durante mucho tiempo, que el presidente al-Assad dimitiese y abandonase el gobierno del país. ${ }^{99}$ Lo mismo volvió a repetirse, tan solo un año después, en abril de 2018, cuando Washington acusó al régimen de haber empleado nuevamente armas químicas en Duma, y, por consiguiente, durante una acción conjunta con Reino Unido y Francia, bombardeó unas instalaciones de almacenamiento y producción de armas químicas y biológicas cerca de Damasco y Homs. ${ }^{100}$ Sin embargo, esto no solo no llevó a una escalada del conflicto y a una actuación estadounidense más decidida y continuada para forzar al presidente

\footnotetext{
92 Abhyankar, op. cit., p. 127.

${ }^{93}$ Rodham Clinton, op. cit., p. 446-470; Kerry, John (2018): Every Day is Extra, New York, Simon \& Shuster, pp. 524-555; Carter, Ash (2019): Inside the Five-Sided Box: Lessons from a Lifetime of Leadership in the Pentagon, New York, Penguin, pp. 295-297.

${ }^{94}$ Carter, op. cit., pp. 226-257.

${ }^{95}$ Ibid., pp. 125 y 128.

${ }^{96}$ Hurtado, Lluís: "Un ataque químico mata al menos a 83 personas en Siria", El Mundo, 7 de abril de 2017, en http://www.elmundo.es/internacional/2017/04/04/58e35091e5fdeaef348b4573.html

${ }^{97}$ Martínez Ahrens, Jan: "Trump ordena atacar con misiles al régimen sirio", El País, 8 de abril de 2017, en https://elpais.com/internacional/2017/04/06/estados_unidos/1491506181_402836.html

98 "Estados Unidos ataca una base aérea siria con 59 misiles en respuesta 'al terrible ataque con armas químicas' del que acusa a Bashar al Asad", BBC Mundo, 7 de abril de 2017, en http://www.bbc.com/mundo/noticiasinternacional-39524024

${ }^{99}$ Henderson, Barney y Allen, Nick: "Donald Trump says he has changed his position on Bashar al-Assad and Syria after chemical weapons attack and has 'responsibility' to act", The Telegraph, 6 April 2017, en http://www.telegraph.co.uk/news/2017/04/05/donald-trump-says-has-changed-position-bashar-al-assad-syria/

100 "Estados Unidos, Francia y Reino Unido lanzan un ataque contra Siria en respuesta al supuesto uso de armas químicas por Bashar al Asad", BBC Mundo, 14 de abril de 2018, en https://www.bbc.com/mundo/noticiasinternacional-43750307
} 
sirio a renunciar al poder, al contrario, Washington, después de comprobar que los yihadistas del Daesh habían sido vencidos y que no era realista creer que al-Assad cayera, decidió que para los Estados Unidos había llegado la "hora de irse" y que otros tenían que resolver la situación, retirando así su apoyo a los combatientes rebeldes, entre los cuales los kurdos, que habían sido hasta entonces sus principales aliados en la guerra contra el Daesh, en el temor de reforzar excesivamente también a grupos islamistas menos moderados. Desde entonces, la Casa Blanca ha adoptado una estrategia enfocada más en mantener en Siria unas fuerzas reducidas, en la actualidad de unos 900 hombres que sirven de apoyo a las fuerzas democráticas sirias que continúan combatiendo al Daesh, personal de inteligencia y fuerzas especiales, así como afianzar su presencia naval y aérea en la región, Como ya vimos, Ankara aprovechó el repliegue estadounidense para invadir el norte de Siria, ${ }^{101}$ provocando graves consecuencias, no solo en la región, sino también en Europa, ya que facilitó la fuga de centenares de yihadistas de los centros de detención establecidos en Siria y produjo una nueva crisis humanitaria en el este de Siria y el oeste de Iraq. ${ }^{102}$

Asimismo, dio un paso controvertido al reconocer la anexión por Israel de los Altos del Golán, en marzo de 2019, creando una nueva línea de ruptura con el régimen de al-Assad y obligando al régimen de al-Assad a reformular su política adoptada en Daraa y Quneitra, en connivencia con Rusia.

La Administración de Biden no ha cambiado sustancialmente la política de su predecesor. En febrero de 2021 se lanzó un primer ataque aéreo contra diversas infraestructuras de dos milicias chiitas, Kataib Hezbollah y Kataib Sayyid al-Shuhada, respaldadas por Irán y aliadas de al-Assad, en respuesta a unos ataques al personal norteamericano y de la coalición internacional de estancia en Erbil, en el Kurdistán iraquí. La nueva Administración enviaba así un mensaje claro a Teherán: el hecho de que nos volvamos a sentar para hablar del acuerdo sobre vuestro programa nuclear no significa que vuestros agentes regionales puedan hacer lo que quieren. ${ }^{103}$ A pesar de todo, en las circunstancias actuales, con el Daesh todavía activo, con la fuerte presencia de Irán y Rusia y con el gobierno de al-Assad que controla la mayor parte del territorio, la presencia de los Estados Unidos es todavía relevante ante el casi vacío occidental y la actividad y ataques que todavía realiza el Daesh, tanto en Iraq como en Siria. ${ }^{104}$ De hecho, hoy en día, la perspectiva más realista sería la de una suerte de protectorado permanente norteamericano en el territorio bajo control kurdo, en un país aún dividido en, al menos, cuatro zonas de influencia (la del régimen apoyado por Irán y Rusia, la de los rebeldes sirios apoyados por el ejército turco, la de los kurdos apoyados por Estados Unidos y la de Israel en el sur). ${ }^{105}$ Esta presencia duradera de las tropas estadounidenses, no obstante, en lugar de influir positivamente, podría aumentar las probabilidades de choques con las fuerzas iraníes, rusas o, incluso, turcas aliadas en la OTAN.

El error de Washington no ha sido tanto el ir retirando progresivamente las tropas de Siria, sino permitir su marginación de las conversaciones diplomáticas, dejando todo el

\footnotetext{
101 Jones, Seth G.: "Developing a Containment Strategy in Syria", Center for Strategic and International Studies, 17 May 2018, en https://www.csis.org/analysis/developing-containment-strategy-syria

${ }^{102}$ Milosevich-Juaristi, Mira: “¿Es Rusia una gran potencia en Oriente Medio?”, Real Instituto Elcano, ARI n 103/2019, 8 de noviembre de 2019, en

http://www.realinstitutoelcano.org/wps/portal/rielcano_es/contenido?WCM_GLOBAL_CONTEXT=/elcano/elca no_es/zonas_es/ari103-2019-milosevichjuaristi-es-rusia-una-gran-potencia-en-oriente-medio

103 "Biden takes first military action with Syria strike on Iran-backed militias", BBC News, 26 de febrero de 2021, en https://www.bbc.com/news/world-middle-east-56205056

${ }^{104}$ Singh, Michael: "U.S. Policy in the Middle East amid Great Power Competition", The Washington Institute for Near East Policy, 30 March 2020, en https://www.washingtoninstitute.org/policy-analysis/us-policy-middle-eastamid-great-power-competition

${ }^{105}$ International Crisis Group, op. cit.
} 
protagonismo y la posible solución del conflicto en manos de Moscú, Teherán y Ankara que, en enero de 2017, inauguraron las llamadas "Conversaciones de Astaná", al margen de Naciones Unidas, una ronda de negociaciones para encontrar una solución negociada al conflicto entre enviados del gobierno de al-Assad e intermediarios de algunos grupos rebeldes que se desarrollan bajo la coordinación y control de Irán, Turquía e Rusia. ${ }^{106}$

Precisamente este último país, Rusia, es la otra potencia internacional involucrada en la cuestión siria cuya participación en la guerra civil queremos mencionar y que, hasta el momento, es la que mejor ha sabido involucrarse en el laberinto sirio, aprovechando el vacío geopolítico y llevando la "voz cantante" después de que los Estados Unidos decidiesen desentenderse del problema por temor a un nuevo Afganistán. Ahora bien, desde los años sesenta se dice que "Israel es a Estados Unidos como Siria ha sido a Rusia"107 o, en otros términos, que Siria ha representado el contrapeso a Israel en Oriente Próximo. Este eje entre Moscú y Damasco se concreta, en particular, en una estrecha colaboración militar que se traduce en el abastecimiento en favor de Siria de armamentos provenientes de Rusia y en el acceso que esta última tiene asegurado a la base naval de Tartús y a la base aérea de Hmeimim cerca de Latakia, ambas a orillas del Mar Mediterráneo. ${ }^{108}$ Esto porque Moscú, ya sea en su época zarista ya sea en el período soviético y en la actualidad, ha buscado siempre mantener avanzadillas defensivas marítimas, al igual que, en tierra, ha procurado mantener Estados colchones o Estados tapones entre su territorio y el de sus principales adversarios. ${ }^{109}$ En particular, la base marítima en Tartús es especialmente importante para los intereses geoestratégicos del Kremlin por tres motivos principales. Antes que nada, se trata de un punto de apoyo clave en el mar Mediterráneo que tiene la flota rusa, lo que permite a sus buques no tener que volver con frecuencia a los puertos en el Mar Negro. Esto permite, asimismo, a Rusia tener un acceso más cómodo al Canal de Suez e incluso al estrecho de Gibraltar. Además, es la puerta principal de entrada a Siria de los pertrechos militares de fabricación rusa. ${ }^{110}$ Con ello puede proyectar su poder sobre Oriente Medió e incluso competir con la propia OTAN, limitando su capacidad de actuación y dividiendo a sus miembros, siendo el caso de Turquía paradigmático. Todo ello, conviene recordarlo, mientras la Marina estadounidense ha reducido notablemente su actividad en el mar Mediterráneo, habiendo desplazado su foco de atención al área del Indico Pacífico. ${ }^{11}$ Al mismo tiempo, ha podido reconfigurar una parte de su poder militar, probando nuevos sistemas de armas, nuevas doctrinas y adiestrando a su personal, y mostrar, de cara a su venta, la efectividad de sus sistemas de armas. Y, lo que no es desdeñable, aparecer como una gran potencia que no abandona a sus aliados antes de conseguir los objetivos propuestos, frente a otras ejemplificaciones de países occidentales, y un gran mediador internacional en la solución

\footnotetext{
106 Pillar, Paul R.: “Donald Trump's Syria Withdrawal: Are We Asking the Right Questions?”, The National Interest, 9 October 2019, en https://nationalinterest.org/blog/paul-pillar/donald-trumps-syria-withdrawal-are-weasking-right-questions-86906

${ }^{107}$ Morales González, Alberto: “QQué intereses tiene Rusia en Siria?”, Instituto Español de Estudios Estratégicos, Documento de opinión, no 48 (2013), pp. 1-14, p. 3, en

http://www.ieee.es/Galerias/fichero/docs_opinion/2013/DIEEEO48-

2013_InteresesRusos_enSiria_MoralesGlez.pdf

${ }^{108}$ Cafarella, Jennifer y Zhou, Jason: "Russia's Dead-End Diplomacy in Syria", Institute for the Study of War, November 2019, pp. 1-51, pp. 11-12, en

http://www.understandingwar.org/sites/default/files/ISW\%20Report\%20-\%20Russia\%E2\%80\%99s\%20DeadEnd\%20Diplomacy\%20in\%20Syria\%20-\%20November\%202019.pdf

109 Thornton, Rod: "Countering Prompt Global Strike: The Russian Military Presence in Syria and the Eastern Mediterranean and Its Strategic Deterrence Role", The Journal of Slavic Military Studies, vol. 32, n 1 (2019), pp. $1-24$, p. 7.

${ }^{110}$ Milosevich-Juaristi, op. cit., p. 1; Morales González, op. cit., pp. 5-7.

111 Altman, Jonathan: "Russian A2/AD in the Eastern Mediterranean: A Growing Risk", Naval War College Review, vol. 69, nº 1 (2016), pp. 72-84, p. 79, en

https://digital-commons.usnwc.edu/cgi/viewcontent.cgi?article=1119\&context=nwc-review
} 
de conflictos, promoviendo la creación de zonas de desescalada, altos del fuego y acuerdos entre partes, obligando al gobierno de al-Assad a aceptar sus condiciones como intermediario y como reorganizador de sus fuerzas armadas. Si bien esta situación siempre ha creado problemas a medio plazo y los Estados más o menos vasallos han acabado revolviéndose contra sus "protectores".

Ahora bien, la participación rusa en la guerra civil siria representa, en realidad, solo un segmento del más amplio plan del Kremlin y, en particular, de su presidente, Vladimir Putin, para volver a ser una gran potencia regional y global que protagonice las relaciones internacionales a expensas de los Estados Unidos y pueda estar a la altura de otra grande potencia como es China. ${ }^{112}$ Como expone Rajendra M. Abhyankar, un factor importante a tener en cuenta para explicar el activismo ruso en Siria es su voluntad arraigada de proyectar a escala internacional su "gran poder" (derzhavnost, en ruso), en el deseo de hacer revivir la supuesta gloria imperial de la Unión Soviética. ${ }^{113} \mathrm{Y}$ ello, en particular, después de las sanciones impuestas por la Unión Europea (tras la anexión de Crimea y el conflicto del Donbás de 2014) ${ }^{114}$ y las que realizaron los Estados Unidos por las interferencias rusas en las elecciones presidenciales norteamericanas de 2016 y $2020 .{ }^{115}$

Así, implicándose directamente en la guerra de Siria desde septiembre de 2015, Rusia ha conseguido cambiar la suerte de un conflicto que parecía destinado a ver el triunfo de los rebeldes y la capitulación de al-Assad, que hubiera así compartido el mismo destino de otros dictadores vecinos (Muamar Gadafi, Hosni Mubarak o Zine Ben Ali). Justificando su intervención con la necesidad de combatir el terrorismo del Daesh y de otras milicias yihadistas, la aviación rusa permitió al régimen fortificar su control en las principales ciudades del país y reconquistar ciudades como la de Alepo, consintiendo, al mismo tiempo, a Rusia tomar las riendas de la situación, haciendo aceptar a al-Assad como el mal menor y volviéndose en el referente principal para resolver el conflicto. Circunstancia que quedó reflejada en los resultados - nada sorprendentes - de las elecciones presidenciales sirias tenidas, en mayo de 2021, en las áreas del país bajo control del régimen, en donde Bashar al-Assad ganó con el $95.1 \%$ de los votos, asegurándose así su cuarto mandato consecutivo. Está claro que se trató de elecciones farsa y, como señalaron los ministros de exteriores del Reino Unido, Francia, Italia, Alemania y Estados Unidos en una declaración conjunta previa al voto, ilegitimas, al no ser ni libres ni imparciales y sin contar con la supervisión de las Naciones Unidas. ${ }^{116}$ Sin embargo,

112 Rodgers, James: "Russia and Syria: Policies, Problems, Perspectives", Forbes, 11 January 2019, en https://www.forbes.com/sites/jamesrodgerseurope/2019/01/11/russia-andsyria-prospects-andprizes/\#2397dfc36852

113 Abhyankar, op. cit., p. 119.

${ }^{114}$ Bermejo García, Romualdo (2015): La vuelta de Crimea a la madre-patria. Algunas reflexiones a la luz del Derecho Internacional, $1^{\text {a }}$ edición, Valencia, Tirant Lo Blanch.

115 Colás, Javier: "Estados Unidos castiga a Rusia con duras sanciones económicas y la expulsión de diez diplomáticos", El Mundo, 15 de abril de 2021, en

https://www.elmundo.es/internacional/2021/04/15/60783034fdddffca048b4646.html; "Trump firma una ley que impone nuevas sanciones a Rusia por su supuesta intervención en las elecciones presidenciales de 2016", BBC News, 2 August 2017, en https://www.bbc.com/mundo/noticias-internacional-40806532

116 Joint Statement by the Secretary of State of the United States of America, the Foreign Secretary of the United Kingdom, and the Foreign Ministers of France, Germany, and Italy, 25 de mayo de 2021: "We, the Foreign Ministers of France, Germany, Italy, the United Kingdom and the United States of America wish to make clear that Syria's May 26 presidential election will neither be free nor fair. We denounce the Assad regime's decision to hold an election outside of the framework described in UN Security Council Resolution 2254 and we support the voices of all Syrians, including civil society organisations and the Syrian opposition, who have condemned the electoral process as illegitimate. As outlined in the Resolution, free and fair elections should be convened under UN supervision to the highest international standards of transparency and accountability. For an election to be credible, all Syrians should be allowed to participate, including internally displaced Syrians, refugees, and members of the diaspora, in a safe and neutral environment. Without these elements, this fraudulent election does 
fueron otra prueba de fuerza, no tanto del dictador sirio, sino de Moscú, dado que si Rusia no hubiera querido la reelección de al-Assad hubiera podido tranquilamente hacer descarrillar la votación, como hace notar Lina Khatib, directora del Programa para Oriente Medio y Norte de África del think tank Chatham House. ${ }^{117}$ Así que, quizás, hablar de "control" por parte de alAssad no sea del todo correcto, porque transmite la sensación de que éste tenga una fuerza que, en realidad, no tiene. La capacidad del régimen de controlar muchas zonas del país depende de la presencia de soldados rusos y de las milicias chiitas apoyadas por Irán y que definen las fronteras de los territorios bajo control gubernamental. ${ }^{118}$ Es más, estas elecciones demuestran también que estamos todavía lejos de asistir a una verdadera transición política de conformidad con las pautas prescritas en la resolución 2254 (2015) del Consejo de Seguridad de la ONU. ${ }^{119}$

Sin olvidar sus lazos con países de orientación política o religiosa muy diferentes (Arabia Saudí, Qatar, Israel, Irán o Turquía, entre los demás), Rusia ha demostrado una capacidad político-diplomática inmejorable que se funda en la idea pragmática de respaldar a quienes están en el poder sin prejuicios ideológicos, sin tener ni aliados ni adversarios en Oriente Próximo. ${ }^{120}$ Así, por ejemplo, sus relaciones con Turquía pese a que estas estén "históricamente cargada[s] de sospechas y fricciones"121 ya que, como ya hemos visto, Ankara se coloca en el polo opuesto del tablero sirio, habiendo entrado en guerra, en una primera fase, con la intención de destituir a Bashar al-Assad. Esto, no obstante, no ha impedido la participación de Turquía en las Conversaciones de Astaná, a partir de enero de $2017^{122}$ y la firma de diversos acuerdos, como el realizado en Sochi en 2018, ${ }^{123}$ para la creación de una zona de seguridad en la frontera que según Erdoğan impediría ya una agenda separatista en territorio sirio, ${ }^{124}$ o el firmado en marzo de 2020, en Moscú, sobre un alto el fuego para la provincia de Idlib, ${ }^{125}$ último bastión de distintos grupos rebeldes en el noroeste del país, después de que las tropas progubernamentales, respaldadas por aviones rusos, tras recuperar amplias parcelas de la provincia y puntos estratégicos como la autopista M5, llegaron a chocarse directamente con el ejército turco (que ocupa esta área en donde se estableció una zona de desescalada) e indirectamente con la inteligencia y la aviación rusa. ${ }^{126}$

not represent any progress towards a political settlement. We urge the international community to unequivocally reject this attempt by the Assad regime to regain legitimacy without ending its grave human rights violations and meaningfully participating in the UN-facilitated political process to end the conflict. We reiterate our firm support for the UN Special Envoy for Syria's efforts to promote a political settlement, based on all aspects of UNSCR 2254, which protects the future prosperity and the rights of all Syrians, including the right to vote in free and fair elections." En https://www.state.gov/joint-statement-by-the-secretary-of-state-of-the-united-states-of-americathe-foreign-secretary-of-the-united-kingdom-and-the-foreign-ministers-of-france-germany-and-italy-2/

${ }^{117}$ Holleis, Jennifer: "Syria's sham election guarantees 1 thing - Bashar Assad will win", Deutsche Welle, 25 May 2021, en https://www.dw.com/en/syrias-sham-election-guarantees-1-thing-bashar-assad-will-win/a-57657900

118 "La Siria, dieci anni dopo", op. cit.

119 S/RES/2254, 18 de diciembre de 2015, en https://undocs.org/es/S/RES/2254(2015) Acerca de la falta de aplicación de lo que contempla esta resolución, véase: Cafarella y Zhou, "Russia's Dead-End Diplomacy in Syria", op. cit., pp. 31-33.

${ }^{120}$ Milosevich-Juaristi, “¿Es Rusia una gran potencia en Oriente Medio?”, op. cit.

${ }^{121}$ Milosevich-Juaristi, “¿Es Rusia una gran potencia en Oriente Medio?”, op. cit.

122 Ibid.

${ }^{123}$ Memorándum para la estabilización de la situación en la zona de desescalada de Idlib, 17 de septiembre de 2018, en https://www.voltairenet.org/article203081.html

${ }^{124}$ McKernan, Bethan y Borger, Julian: "Turkey and Russia agree on deal over buffer zone in northern Syria", The Guardian, 22 October 2019, en https://www.theguardian.com/world/2019/oct/22/turkey-and-russia-agree-dealover-buffer-zone-in-northern-syria

${ }^{125}$ Additional Protocol to the Memorandum on Stabilization of the Situation in the Idlib De-Escalation Area, 6 March 2020, en

https://www.mid.ru/en/foreign_policy/news/-/asset_publisher/cKNonkJE02Bw/content/id/4072593

${ }^{126}$ Sánchez Tapia, op. cit., p. 7. 
Y también sus relaciones con Israel, pensemos en las relaciones entre Vladimir Putin y Benjamin Netanyahu que llevaron a la firma de un acuerdo de no-conflictividad (deconflictual agreement) en septiembre de 2015, por el cual Israel notificaría previamente a los rusos sobre un próximo ataque de su aviación, generalmente unas horas antes de que tuviera lugar. El acuerdo, en la práctica, significaba que las defensas aéreas rusas no iban a responder en términos generales a las incursiones notificadas de la Fuerza Aérea de Israel. Pero, una vez que se produjo un grave incidente con el derribo por las baterías sirias de un IL-20 ruso, tras una maniobra israelí, la defensa aérea fue reforzada por Rusia, e Israel varió de táctica utilizando armas de precisión lanzadas a larga distancia desde el aire, generalmente desde territorio del Líbano. ${ }^{127}$ Y, en otro orden, obligando al gobierno de al-Assad a excluir a las milicias de Irán y Hezbollah en su campaña en el sur, en Daraa y Quneitra, y aceptar las negociaciones con grupos rebeldes, llegándose al acuerdo de 2018 y evitando una escalada militar que podría implicar a sus vecinos fronterizos, si bien Rusia en los últimos meses ha permitido un mayor control de Damasco sobre la zona ${ }^{128}$ y su consolidación en función de la nueva política de Jordania, a la que la administración Biden no puso freno, admitiendo que el colapso del régimen de Damasco era ya una ilusión, como ya admitían la mayoría de los demás países árabes y se pudo demostrar en la reunión del ministro de Asuntos Exteriores sirio con diez ministros de Asuntos Exteriores de otros Estados árabes en Nueva York, con motivo de la 76 Asamblea General de Naciones Unidas. Era la primera vez que ocurría algo parecido desde hacía diez años, si bien su readmisión en la Liga Árabe no tendía todavía el consenso de todos los miembros. En este contexto hay que entender el plan de llevar el gas de Egipto vía Jordania y Siria hasta el Líbano y la necesidad de estabilizar el sur de Siria ${ }^{129}$

Además de estos sucesos en diversos campos de batalla, hay que mencionar de nuevo el derribo de un caza ruso por parte de Turquía en noviembre de 2015, así como el asesinato de Andrey Karlov, embajador ruso en Turquía en diciembre de 2016, hechos directamente relacionados con la intervención de Rusia en Siria. Frente a ellos, la reacción rusa fue muy fuerte, poniendo en un brete al presidente Erdoğan e incluso en febrero de 2016 permitió al PYD abrir una oficina en Moscú. Estas medidas y las prioridades de seguridad nacional forzaron a Turquía a una colaboración "antinatural" con Rusia e Irán para así poder llegar a controlar en lo posible a los kurdos de Siria lindantes con la frontera turca e imposibilitarles apoyar a los kurdos de Turquía en su objetivo de instaurar un Kurdistán sirio. Además, existían otros intereses conjuntos como la venta y transporte de gas vía Turquía (Blue Stream y TurkStream), la venta de sistemas antiaéreos S-400 con cesión de tecnología, o la colaboración en la construcción de un reactor nuclear en Turquía. Con esta colaboración, Rusia intentaba debilitar la cohesión de la OTAN e incluso a la Unión Europea en su política de diversificación energética y de apoyo a Ucrania. No obstante, la mejora de las relaciones entre los dos Estados se juega también en los acontecimientos de Libia, otro conflicto en que ambos países están involucrados y enfrentados y que está estrechamente relacionado con el de Siria. ${ }^{130}$

El protagonismo ruso se ha hecho patente, no solo en los cielos sirios y en numerosas sedes diplomáticas de Oriente Próximo, sino que también en el seno del Consejo de Seguridad de la ONU, en donde Moscú no ha dudado ni un momento en ejercer su derecho de veto toda

\footnotetext{
${ }^{127}$ Bryen, Stephen D.: "Russia, Israel Need Working Accord on Syria", San Diego Jewish World, 11 September 2021, en https://www.sdjewishworld.com/2021/09/11/russia-israel-need-working-accord-on-syria/

128 Tokmajyan Armenak: Unfinished Business in Daraa, Carnegie Middle East Center, 25 August 2021, en https://carnegie-mec.org/diwan/85200

129 Tokmajyan Armenak: Cracks in the Wall, Carnegie Middle East Center, 7 October 2021, en https://carnegiemec.org/diwan/85524. Stephen Laure: Dans la region de Deraa, le retour Chaotique du régime Assad, Le Monde 5 octobre 2021 en https://www.lemonde.fr/international/article/2021/10/05/dans-la-region-de-deraa-le-retourchaotique-du-regime-assad_6097240_3210.html

${ }^{130}$ Sánchez Tapia, op. cit., p. 16.
} 
vez que lo ha estimado necesario para amparar al régimen de Damasco. Ya en abril de 2011, cuando el Consejo de Seguridad se reunió por primera vez para considerar la situación en Siria después de los primeros incidentes en el país, Rusia se apresuró en recalcar que:

“[L]a actual situación en Siria, pese a las tensiones y los enfrentamientos cada vez mayores, no presenta una amenaza para la paz y la seguridad internacionales. No se puede pasar por alto el hecho de que la violencia no se origina totalmente en uno de los bandos. [...] A nuestro juicio, una amenaza real para la seguridad regional podría originarse debido a la injerencia externa en la situación interna de Siria, incluidos los intentos por promover soluciones ya listas o por tomar partido". ${ }^{131}$

Al hilo de estas justificaciones, desde entonces, Moscú ha vetado 17 proyectos de resoluciones, 9 de los cuales también con el veto de China, que pudieran de alguna manera perjudicar a la dictadura siria y, con ella, sus objetivos estratégicos en el país. ${ }^{132}$ Una de las primeras manifestaciones claras de la renuencia del Kremlin a cualquier acción que amenace la supervivencia del régimen sirio llegó en 2013, después de que este perpetrara el primero de sus ataques químicos con gas sarín cerca de Damasco, provocando la muerte de entre 900 y 1.400 personas. ${ }^{133}$ En aquella ocasión, los Estados Unidos plantearon recurrir a la fuerza armada, obligando Moscú a buscar una salida diplomática e impedir así una operación militar que hubiese significado el fin de la dictadura de la familia al-Assad y el deterioro consecuente de la posición rusa en Siria. ${ }^{134}$ Por lo tanto, con la resolución 2118 (2013), el Consejo obligó al gobierno sirio a comunicar la cantidad precisa de arsenal químico y a entregarlo en su totalidad, además de consentir al ingreso en el país de los inspectores internacionales encargados de averiguar la obediencia a esta Resolución. ${ }^{135}$ No obstante, lo que interesa señalar de la Resolución 2118 (2013) es que, a la vez que amonesta a que "ninguna parte en Siria" use, desarrolle, produzca, adquiera, almacene, conserve, ni transfiera armas químicas, ${ }^{136}$ no se pronuncia acerca de la autoría del ataque químico. Al menos, en aquella ocasión, el Consejo consiguió ponerse de acuerdo para adoptar una resolución. Circunstancia que no volvió a repetirse con ocasión de los sucesivos ataques perpetrados con armas químicas, de abril de 2017 y de abril 2018, después de los cuales, Rusia ejercitó en seis ocasiones su derecho de veto para bloquear proyectos de resoluciones dirigidas a sancionar a Siria por el uso de armas químicas, ampliar el plazo del Mecanismo Conjunto de Investigación de la Organización para la Prohibición de las Armas Químicas (OPAQ) y las Naciones Unidas que investigaba lo acontecido y crear un nuevo mecanismo de investigación de los hechos y de determinación de los responsables. ${ }^{137}$ Para dar cuenta de la desconfianza rusa y de la acritud del debate dentro del Consejo sobre el asunto de las armas químicas, valga como botón de muestra la opinión del representante ruso, el señor Nebenzia, acerca del Mecanismo Conjunto de Investigación, que consideraba padecer de "lagunas que dieron pie a que las investigaciones fueran manipuladas y entregadas al control de los detractores de Damasco [...]". ${ }^{138}$ Claro está que, con base en estas

\footnotetext{
${ }^{131}$ S/PV. 6524, 27 de abril de 2011, declaración del representante de Rusia, Sr. Pankin, p. 8.

${ }^{132}$ Para el listado completo de los vetos rusos y chinos, véase: https://research.un.org/es/docs/sc/quick/veto

133 "Attacks on Ghouta: Analysis of Alleged Use of Chemical Weapons in Syria", Human Rights Watch, 10 September 2013, en https://www.hrw.org/report/2013/09/10/attacks-ghouta/analysis-alleged-use-chemicalweapons-syria

134 "Cuenta regresiva para Siria: EE. UU. concluye que usó armas químicas", El País, 27 de agosto de 2013, en http://www.elpais.com.uy/mundo/cuenta-regresiva-siria-estados-unidos.html; Lain, Sarah y Sutyagin, Igor: "The View from Moscow", en Bassiri Tabrizi Aniseh y Pantucci, Raffaello (eds.) (2016): Understanding Iran's Role in the Syrian Conflict, London, Ed. Royal United Services Institute for Defence and Security Studies, pp. 17-25, p. 17.

${ }^{135}$ S/RES/2118, 27 de septiembre de 2013, preámbulo, párr. 13, y dispositivo, párrs. 3 y 7.

136 Ibid., dispositivo, párr. 5.

137 Véase: https://research.un.org/es/docs/sc/quick/veto

${ }^{138}$ S/PV. 8228, 10 de abril de 2018, declaración del representante de Rusia, Sr. Nebenzia, p. 9.
} 
premisas, llegar a una solución política de la crisis siria que vea involucradas tanto las potencias occidentales como las orientales, va a ser muy complicado. La postura de Moscú, acompañada en varias ocasiones (ocho) del veto de China, ha forzado, de nuevo, el Consejo de Seguridad a un inmovilismo que genera no poca frustración e impotencia en los que vamos observando los acontecimientos sirios sin ver la luz al final del túnel. Así lo subrayó también el Enviado Especial para Siria, Geir O. Pedersen, amonestando a los Estados miembros del Consejo de Seguridad de que, mientras los actores clave estén más volcados en la gestión del conflicto que en su resolución, Siria será otro conflicto destinado a durar por generaciones. ${ }^{139}$

Solo en relación con la distribución de ayuda humanitaria - y no sin vacilaciones ni trabas - el Consejo pudo hacer el trabajo por el cual se creó. Después de que Rusia y China bloquearan, en tres ocasiones, la adopción de resoluciones dirigidas a permitir el envío de ayuda humanitaria a la población siria, por fin, con la resolución $2533(2020)^{140}$ pudieron prorrogarse durante otros 12 meses las previsiones de los párrafos 2 y 3 de la resolución 2165 (2014), ${ }^{141}$ que prevén un mecanismo de envío transfronterizo de ayuda humanitaria y que se aplicarán por tanto hasta el 10 de julio de 2021, pero con exclusión de los cruces fronterizos de al-Ramtha (en la frontera entre Siria y Jordania), al-Yarubiyah (entre Siria e Iraq) y Bab al-Salam (entre Siria y Turquía), secundado así el proyecto de resolución ruso S/2020/683 de 13 de julio de $2020 .{ }^{142}$ En concreto, el mencionado párrafo 2 decide que los organismos humanitarios de la ONU están autorizados a utilizar rutas a través de las líneas del conflicto y los cruces fronterizos de Bab al-Salam, Bab al-Hawa (entre Siria y Turquía), Al Yarubiyah y Al-Ramtha, además de los que ya se están utilizando, para asegurar que la asistencia humanitaria, incluidos los suministros médicos y quirúrgicos, llegue a las personas necesitadas en toda Siria por las rutas más directas, con notificación a las autoridades sirias; destacando, para ello, la necesidad de que todos los cruces fronterizos se utilicen con eficiencia para las operaciones humanitarias. Del mismo modo, el sucesivo párrafo 3 decide establecer un mecanismo de vigilancia, bajo la autoridad del Secretario General de la ONU, para vigilar, con el consentimiento de los correspondientes países vecinos de Siria, la carga de todos los envíos de socorro humanitario de los organismos humanitarios de las Naciones Unidas en las instalaciones pertinentes de la ONU, y toda apertura posterior de esos envíos por las autoridades aduaneras de los correspondientes países vecinos, para su entrada en Siria por los cruces fronterizos de Bab al-Salam, Bab al-Hawa, Al Yarubiyah y Al-Ramtha, con notificación de las Naciones Unidas a las autoridades sirias, a fin de confirmar la naturaleza humanitaria de estos envíos de socorro. Con lo cual, se puede apreciar como la resolución 2533 (2020), que refleja el borrador ruso, permite tan solo un cruce fronterizo abierto, el de Bab al-Hawa, para consentir la entrada de la ayuda humanitaria en territorio sirio, cortando así drásticamente el acceso directo a comida, asistencia médica y educación a millones de personas. ${ }^{143}$

En definitiva, gracias a su habilidad para acomodarse a escenarios en constante transformación, a su efectividad militar y a su eficaz esfuerzo diplomático, Moscú parece haber conseguido prácticamente todos los objetivos que se había fijado para Siria: 1) evitar la destitución de al-Assad, 2) reforzar los vínculos económicos con los demás Estados de la región

\footnotetext{
${ }^{139}$ SC/ 14531, "If Syria's Key Players Remain 'More Invested in Conflict Management Than Conflict Resolution', Fighting Could Last Generations, Envoy Tells Security Council", Comunicado de prensa del Consejo de Seguridad, 26 de mayo de 2021, en https://www.un.org/press/en/2021/sc14531.doc.htm

${ }^{140} \mathrm{~S} / \mathrm{RES} / 2533,13$ de julio de 2020, en https://undocs.org/es/S/RES/2533\%20(2020)

${ }^{141} \mathrm{~S} / \mathrm{RES} / 2165,14$ de julio de 2014, en https://undocs.org/es/S/RES/2165(2014)

${ }^{142}$ S/2020/683, 13 de julio de 2020, en https://undocs.org/es/S/2020/683

143 "ONU: Deleznable veto de Rusia y China a una ayuda humanitaria vital para millones de civiles en Siria", Amnistía Internacional, 7 de julio de 2020, en https://www.amnesty.org/es/latest/news/2020/07/un-russia-andchina-launch-despicable-veto-of-lifesaving-aid-for-millions-of-civilians-in-syria/
} 
y 3) actuar como interlocutor de referencia en los conflictos locales. ${ }^{144}$ No obstante, cabe decir, por último, que si es cierto que su presencia militar le asegura a Rusia una posición privilegiada en Oriente Próximo en este breve periodo, esto no implica que pueda ejercer durante mucho tiempo su influencia en la región sin los recursos económicos necesarios para la reconstrucción de Siria. Al hilo de esta consideración, Moscú ha conseguido que al-Assad se mantuviera en el gobierno del país, pero la economía rusa parece demasiado frágil para soportar los costes de la futura reconstrucción y del fortalecimiento de la estructura estatal sirias, ${ }^{145}$ y su presencia e influencia deberá de reconfigurarse para no ser un elemento de profunda distorsión de la soberanía de Siria.

\section{Consideraciones finales}

Serían suficientes los datos y números referidos en la introducción de este artículo para resumir de manera eficaz la situación actual en Siria, después de diez años de una guerra civil comenzada para reclamar un espacio para aquellos valores democráticos que los Estados intervinientes han ido poco a poco arrinconando para privilegiar sus objetivos geoestratégicos. De esta manera, el conflicto se ha convertido en una contienda internacional para conseguir ejercer la mayor influencia posible en aquellas porciones del país, cerca de un $40 \%$ de su territorio, que todavía no han vuelto bajo el control del régimen. La guerra ha dejado así al descubierto las fragilidades propias de una comunidad internacional que se caracteriza por una voluntad política excesivamente débil, por la preminencia de las preocupaciones nacionales y partidistas y por un Consejo de Seguridad de la ONU incapaz de dar las respuestas apropiadas debido a la contraposición interna entre Occidente y Oriente sobre este asunto. Todo ello ha convertido a Siria y su población civil en el centro de una infección propia de esta guerra subsidiaria y sectaria, sin terminación aparente, que tiene como telón de fondo las "Guerra Frías" entre Rusia y los Estados Unidos y sus sendos aliados, de un lado, e Irán y Arabia Saudita y sus respectivos socios, del otro. Demuestra bien esta circunstancia el hecho de que la dictadura de al-Assad siga en el poder a pesar de que su gobierno no se haya esforzado realmente para aprobar aquellas reformas democráticas que los ciudadanos sirios pedían con gran estruendo en 2011. En el plano interno, el régimen goza todavía del apoyo amplio por parte de elementos centrales del Estado como son el ejército y los servicios de inteligencia. Siria, además, es un Estado pluralista, una peculiaridad respecto a otros Estados de Oriente Próximo, ya que sunníes, drusos y cristianos también ocupan puestos claves en las esferas gubernamentales, lo que ha permitido a al-Assad gozar también del apoyo de importantes Fuerzas Armadas árabe-sunníes de otros países, esto es, las de Egipto y de Argelia. Como vimos, en el plano internacional, gracias al respaldo iraní y ruso, el régimen ha podido recuperar el control de zonas esenciales del país. Su ubicación geográfica, a orillas del Mediterráneo y en la encrucijada del mundo árabe, hacen de Siria un eje geopolítico cardinal, lo que ha empujado a Rusia e Irán a colaborar militar y políticamente con al-Assad, permitiéndole seguir en el poder. Al mismo tiempo, buena parte de la comunidad internacional involucrada parece haber renunciado a su destitución, como ejemplifican los debates de los últimos dos años dentro de la Liga Árabe para una posible reincorporación de Siria a la Organización, la reapertura de algunas embajadas de Estados del Golfo Arábigo en Damasco, las conversaciones diplomáticas sobre la posibilidad de desempolvar los acuerdos comerciales suspendidos a causa de la guerra y los de vuelos comerciales directos entre Siria, Iraq, Emiratos Árabes Unidos, Bahréin y Omán. Al mismo tiempo, a los Estados occidentales, encabezados por los Estados Unidos, dejando de lado el papel de Francia, y potencias regionales como Arabia Saudita y Turquía, pese a sus proclamas contra el régimen de al-Assad y el respaldo militar y logístico a algunos grupos rebeldes, les ha faltado esa misma "determinación absoluta" puesta en combatir al Daesh para derrocar al

\footnotetext{
${ }^{144}$ Milosevich-Juaristi, “¿Es Rusia una gran potencia en Oriente Medio?”, op. cit.

145 Ibid.
} 
dictador sirio. Las experiencias deducidas de sonoros fracasos y el miedo a que los arsenales prometidos a los insurgentes pudieran acabar de nuevo en manos de grupos extremistas como el Daesh y, por ende, volverse en contra de sus intereses, ha determinado que Occidente y parte de Oriente Próximo reformulasen sus prioridades, entre las que ya no se encuentra la destitución de al-Assad.

Es esta falta de voluntad de los actores internacionales involucrados para resolver el conflicto, y no solo para gestionarlo, lo que hace de la guerra siria un callejón sin salida. Por lo que, concluyendo y contestando a la pregunta que nos planteamos al principio de este artículo (¿está acabada la guerra civil siria?) la respuesta no puede ser ni sí ni no. Desde el punto de vista occidental, tal vez, podríamos contestar que sí, el conflicto se ha dado por terminado, puesto que la operación Determinación absoluta ha logrado su objetivo principal de derrotar al Daesh (aunque está por ver que no se pueda producir su resurgimiento, dados lo efectivos con que todavía cuenta y la persistencia del sectarismo y división que dio lugar a su origen). Del mismo modo, los Estados occidentales ya renunciaron hace tiempo a conseguir el otro objetivo declarado de la actuación militar en Siria, esto es, inducir a al-Assad a ceder las riendas del gobierno del país. Por otro lado, si abordamos la pregunta desde la perspectiva oriental, concretamente desde el punto de vista ruso, iraní, turco, israelí o saudita (entre otros), no podemos decir que para estos países el conflicto interno sirio pueda considerarse concluido. Al revés, el repliegue regional y de efectivos estadounidenses y la falta de mayor determinación por parte de los demás países occidentales les han dado carta blanca para utilizar todas sus herramientas - militares, económicas, diplomáticas, religiosas... - para sacar el mayor partido posible del polvorín sirio, incentivándoles así a gestionar el conflicto o bien, en aras de buscar resolverlo, siendo moneda de cambio, o incluso mantenerlo abierto en función de sus peculiares y divergentes intereses nacionales. La Unión Europea, de nuevo, está prácticamente ausente de lo que ocurre en la conformación de su vecindario.

\section{Bibliografía}

Abhyankar, Rajendra M. (2020): Syria: The Tragedy of a Pivotal State, Singapur, Palgrave Macmillan, 283 pp.

Additional Protocol to the Memorandum on Stabilization of the Situation in the Idlib DeEscalation Area, 6 March 2020, en https://www.mid.ru/en/foreign_policy/news//asset_publisher/cKNonkJE02Bw/content/id/4072593

Ahmadian, Hassan y Mohseni, Payam: "Iran's Syria strategy: the evolution of deterrence", International Affairs, vol. 95, $\mathrm{n}^{\mathrm{o}} 2$ (2019), $\mathrm{pp}$. 341-364, en https://academic.oup.com/ia/article/95/2/341/5306386?login=true

Altman, Jonathan: "Russian A2/AD in the Eastern Mediterranean: A Growing Risk", Naval War College Review, vol. 69, $\mathrm{n}^{\mathrm{o}} 1$ (2016), pp. 72-84, en https://digitalcommons.usnwc.edu/cgi/viewcontent.cgi?article $=1119 \&$ context=nwc-review

Altunişik, Meliha Benli: “Turkey in 2014: Juggling Domestic and Foreign Policy Challenges”, IEMed., Mediterranean Yearbook (2015), pp. 213-216, en https://www.iemed.org/actualitat/noticies/observatori/arees-danalisi/arxius-

adjunts/anuari/med.2015/IEMed\%20Yearbook\%202015_Panorama_Turkey_MelihaBenliAltu nisik.pdf 
Ambos, Kai: "Our terrorists, your terrorists? The United Nations Security Council urges states to combat 'foreign terrorist fighters', but does not define 'terrorism'", EJIL: Talk!, 2 October 2014, en http://www.ejiltalk.org/our-terrorists-your-terrorists-the-united-nations-securitycouncil-urges-states-to-combat-foreign-terrorist-fighters-but-does-not-define-terrorism/

Ansari, Ali y Bassiri Tabrizi, Aniseh: "The View from Tehran", en Bassiri Tabrizi, Aniseh y Pantucci, Raffaello (eds.) (2016): Understanding Iran's Role in the Syrian Conflict, London, Royal United Services Institute for Defence and Security Studies, pp. 3-11

Arteaga, Félix: "Guerra civil en Siria, tercer acto: la invasión turca”, Real Instituto Elcano, Comentario Elcano, $\mathrm{n}^{\mathrm{o}}$ 25/2019, 16 de octubre de 2019, en http://www.realinstitutoelcano.org/wps/portal/rielcano_es/contenido?WCM_GLOBAL_CON TEXT=/elcano/elcano_es/zonas_es/comentario-arteaga-guerra-civil-en-siria-tercer-actoinvasion-turca

-: "Obama: leading from behind", Real Instituto Elcano, Blog Elcano, 13 de septiembre de 2013, en http://www.blog.rielcano.org/obama-leading-from-behind-congress-polls/

Asseburg, Muriel: "All Eyes on the Islamic State? Repercussions of the Fight against Jihadists on War-Torn Syria", IEMed., Mediterranean Yearbook (2015), pp. 1-4, en https://www.iemed.org/observatori/arees-danalisi/arxius-

adjunts/anuari/med.2015/IEMed_MedYearbook2015_All_Eyes_on_the_Islamic_State_Murie $1 \% 20$ Asseburg.pdf

Barker, Brig: "ISIS: Nothing New Under The Sun", Journal of Counterterrorism \& Homeland Security International, vol. 20, nº 4 (2014), pp. 10-12

Barthelmess, Benedikt y Carson, Liam: "How is the crisis in Lebanon impacting Syria's economy?", Middle East Institute, 28 August 2020, en https://www.mei.edu/publications/howcrisis-lebanon-impacting-syrias-economy

Bermejo García, Romualdo (2015): La vuelta de Crimea a la madre-patria. Algunas reflexiones a la luz del Derecho Internacional, $1^{\text {a }}$ edición, Valencia, Tirant Lo Blanch, 139 pp.

Bramon, Dolors: “La confusión del 'jihad”, IEMed. Focus Article, vol. 113 (2014), pp. 1-3, en https://www.iemed.org/observatori/arees-danalisi/arxius-adjunts/copy_of_focus/113-jihad.pdf

Cafarella, Jennifer y Zhou, Jason: "Russia's Dead-End Diplomacy in Syria”, Institute for the Study of War, November 2019, pp. 1-51, pp. 11-12, en http://www.understandingwar.org/sites/default/files/ISW\%20Report\%20-

$\% 20$ Russia\%E2\%80\%99s\%20Dead-End\%20Diplomacy\%20in\%20Syria\%20-

$\% 20$ November\%202019.pdf

Cagaptay, Soner: “Erdoğan's 'Mini Empire' in Libya and Syria”, Turkeyscope, vol. 4, no 3 (January-February 2020), pp. 1-7, en https://www.washingtoninstitute.org/media/726

Cagaptay, Soner y Yolbulan, Cem: “Turkey at a Crossroads”, IEMed., Mediterranean Yearbook (2016), pp. 51-56, en https://www.iemed.org/observatori/arees-danalisi/arxiusadjunts/anuari/med.2016/IEMed_MedYearBook2016_Turkey\%20at\%20a\%20Crossroad_Cag apatay_Yalbulan.pdf

Carter, Ash (2019): Inside the Five-Sided Box: Lessons from a Lifetime of Leadership in the Pentagon, New York, Penguin, 336 pp.

Cebul, Matthew: "Operation 'Peace Spring' and U.S. Strategy in Syria”, Foreign Policy Research Institute, 11 October 2019, en https://www.fpri.org/article/2019/10/operation-peacespring-and-u-s-strategy-in-syria/ 
Cocchini, Andrea: "El Estado Islámico y la geopolítica: el enemigo de mi enemigo es mi amigo... ¿o no?”, en Gutiérrez Espada, Cesáreo y Cervell Hortal, María José (dirs.) (2018): El Estado Islámico (Daesh): ¿Aprenderemos la lección?, Valencia, Tirant lo Blanch, pp. 45-92

Clinton, Hillary Rodham (2014): Hard Choices, New York, Simon \& Shuster, 560 pp.

Cronin, Audrey Kurth: "ISIS Is Not a Terrorist Group: Why Counterterrorism Won't Stop the Latest Jihadist Threat", Foreign Affairs, vol. 94, no 2 (2015), pp. 87-98

Dekel, Udi y Valensi, Carmit: “After a Decade of War in Syria, Israel Should Change its Policy", The Institute for National Security Studies, 7 April 2021, en https://www.inss.org.il/publication/israel-assad/?offset=10\&posts=3116

Djalili, Mohammad-Reza y Kellner, Thierry: "Scramble for Syria", The Cairo Review of Global Affairs, 2017, pp. 1-6, en https://www.thecairoreview.com/wp-content/uploads/2017/07/cr26kellner.pdf

Echeverría Jesús, Carlos: "El Estado Islámico (EI) como grupo terrorista yihadista salafista y otros grupos armados violentos actuando en Irak hoy", Instituto Español de Estudios Estratégicos, Documento de investigación, $\mathrm{n}^{\mathrm{o}} 6$ (2014), pp. 1-15, en http://www.ieee.es/Galerias/fichero/docs_investig/2014/DIEEEINV06-

2014_EstadoIslamico_CarlosEcheverria_.pdf

-: "El desafío terrorista de Boko Haram en Nigeria", Instituto Español de Estudios Estratégicos, Documento de investigación, $\mathrm{n}^{\circ} 2$ (2014), pp. 1-17, en http://www.ieee.es/Galerias/fichero/docs_investig/2014/DIEEEINV022014_Region_Africa_subsahariana_C.Echeverria.pdf

Fillingham, Zachary: “Is Islamic State a State?", Geopolitical Monitor, 5 de agosto de 2015, en https://www.geopoliticalmonitor.com/is-islamic-state-a-state/

Frantzman, Seth J.: "Israel's Uphill Battle with Iran in Syria", The National Interest, 3 de febrero de 2019, en https://nationalinterest.org/feature/israels-uphill-battle-iran-syria-42942

Friedman, Brandon: "US Engagement and Disengagement in the Middle East: Paradox and Perception", The Institute for National Security Studies, vol. 24, no 1 (2021), pp. 136-153, en https://www.inss.org.il/publication/us-engagement-and-disengagement-in-the-middle-eastparadox-and-perception/

González Francisco, Luis: "Wilāyat Saynā': la 'provincia' de Daesh en el Sinaí egipcio", Instituto Español de Estudios Estratégicos, Documento de opinión, no 81 (2016), pp. 1-14

González Hernández, Manuel: "Definiendo términos: fundamentalismo, salafismo, sufismo, islamismo, wahabismo", Instituto Español de Estudios Estratégicos, Documento de opinión, ${ }^{\circ}$ 88 (2015), pp. 1-12, en http://www.ieee.es/Galerias/fichero/docs_opinion/2015/DIEEEO88Antiislamismo_MGlezHdez.pdf

Gunaratna, Rohan: "Global Terrorism in 2016", Revista UNISCI, n 40 (2016), pp. 133-138

Hasan, Harith y Khaddour, Kheder: "The Transformation of the Iraqi-Syrian Border: From a National to a Regional Frontier", Carnegie Endowment for International Peace, marzo de 2020, pp. 1-29, pp. 16-21, en https://carnegieendowment.org/files/Hasan_Khaddour_IraqSyria_Border2.pdf

International Crisis Group: “After Ten Years of War, Conflict Still Paralyses Syria”, 15 March 2021, en https://www.crisisgroup.org/middle-east-north-africa/eastern-mediterranean/syria/after-tenyears-war-conflict-still-paralyses-syria 
Jones, Seth G.: "Developing a Containment Strategy in Syria", Center for Strategic and International Studies, 17 May 2018, en https://www.csis.org/analysis/developing-containmentstrategy-syria

Jordán Enamorado, Javier: "Introducción”, Instituto Español de Estudios Estratégicos, Cuadernos de Estrategia, $\mathrm{n}^{\circ} 180$ (2016), pp. 9-19, p. 10, en https://www.uma.es/foroparalapazenelmediterraneo/wp-content/uploads/2016/10/ce-180estrategia-para-derrotar-al-daesh.pdf

-: "La intervención militar de Rusia en Siria: oportunidades y riesgos", Instituto Español de Estudios Estratégicos, Documento marco, $\mathrm{n}^{\mathrm{o}} 27$ (2015), pp. 1-22, p. 10, en $\mathrm{http} / / / \mathrm{www}$. ieee.es/publicaciones-new/documentos-marco/2015/DIEEEM27-2015.html

Katz, Mark N.: "The Russian Approach to Middle East Conflicts and the Arab World", IEMed., Mediterranean Yearbook (2016), pp. 28-32, en https://www.iemed.org/observatori/areesdanalisi/arxius-

adjunts/anuari/med.2016/IEMed_MedYearBook2016_Russian\%20Approach\%20Middle\%20 East_Mark_Katz.pdf

Kerry, John (2018): Every Day is Extra, New York, Simon \& Shuster, 640 pp.

Lain, Sarah y Sutyagin, Igor: “The View from Moscow”, en Bassiri Tabrizi Aniseh y Pantucci, Raffaello (eds.) (2016): Understanding Iran's Role in the Syrian Conflict, London, Ed. Royal United Services Institute for Defence and Security Studies, pp. 17-25

Layne, Christopher: "From Preponderance to Offshore Balancing: America's Future Grand Strategy", International Security, vol. 22, no 1 (1997), pp. 86-124

Lister, Charles: "2021 will be a defining year for Syria”, Middle East Institute, 12 January 2021, en https://www.mei.edu/publications/2021-will-be-defining-year-syria

Martín Rodríguez, Javier (2015): Estado Islámico: Geopolítica del caos, Madrid, Catarata, 112 pp.

McMaster H.R. (2020): Battlegrounds. The Fight to Defend the Free World, London, William Collins, 545 pp.

Memorándum para la estabilización de la situación en la zona de desescalada de Idlib, 17 de septiembre de 2018, en https://www.voltairenet.org/article203081.html

Memorandum on the creation of de-escalation areas in the Syrian Arab Republic, 6 May 2017, en

https://www.mid.ru/en/foreign_policy/news/-

/asset_publisher/cKNonkJE02Bw/content/id/2746041

Milosevich-Juaristi, Mira: “¿Es Rusia una gran potencia en Oriente Medio?”, Real Instituto Elcano, ARI $\mathrm{n}^{\circ} 103 / 2019, \quad 8$ de noviembre de 2019, en http://www.realinstitutoelcano.org/wps/portal/rielcano_es/contenido?WCM_GLOBAL_CON TEXT=/elcano/elcano_es/zonas_es/ari103-2019-milosevichjuaristi-es-rusia-una-granpotencia-en-oriente-medio

-: "La finalidad estratégica de Rusia en Siria y las perspectivas de cumplimiento del acuerdo de Astaná", Real Instituto Elcano, ARI, n ${ }^{\circ} 43 \quad$ (2017), en http://www.realinstitutoelcano.org/wps/portal/rielcano_es/contenido?WCM_GLOBAL_CON TEXT=/elcano/elcano_es/zonas_es/mediterraneo+y+mundo+arabe/ari43-2017milosevichjuaristi-finalidad-estrategica-rusia-siria-acuerdo-astana 
Morales González, Alberto: “¿Qué intereses tiene Rusia en Siria?”, Instituto Español de Estudios Estratégicos, Documento de opinión, $\mathrm{n}^{\mathrm{o}} 48$ (2013), pp. 1-14, en http://www.ieee.es/Galerias/fichero/docs_opinion/2013/DIEEEO48-

2013_InteresesRusos_enSiria_MoralesGlez.pdf

Nader, Alireza: "Iran's Goals in Syria”, The RAND Blog, 1 January 2015, en https://www.rand.org/blog/2015/01/irans-goals-in-syria.html

Ortega, Andrés: "El califato, una idea con territorio", Real Instituto Elcano, Blog Elcano, 7 de julio de 2015, en http://www.blog.rielcano.org/el-espectador-global-califato-una-ideaterritorio/

Özel, Isik: "Surrounded by trouble, hit by conflict: Turkey and its manifold challenges", Real Instituto Elcano, ARI, $\mathrm{n}^{\mathrm{o}} 4 / 2016,18$ de enero de 2016, en http://www.realinstitutoelcano.org/wps/portal/rielcano_en/contenido?WCM_GLOBAL_CON TEXT=/elcano/elcano_es/zonas_es/mediterraneo+y+mundo+arabe/ari4-2016-ozelsurrounded-by-trouble-hit-by-conflict-turkey-manifold-challenges

Pardo de Santayana Gómez de Olea, José: "Rusia y EEUU en el laberinto de Oriente Próximo", Instituto Español de Estudios Estratégicos, Documento de análisis, no 28 (2017), pp. 1-15, en http://www.ieee.es/Galerias/fichero/docs_analisis/2017/DIEEEA28-2017_EEUU-Rusia-

Laberinto-OrienteMedio_JMPSGO.pdf

Phillips, Christopher, "Syria war: Will the Arab League welcome back Assad", Middle East Eye, 15 March 2021, en https://www.middleeasteye.net/opinion/syria-war-assad-arab-leaguewelcome-back-will

Pillar, Paul R.: “Donald Trump's Syria Withdrawal: Are We Asking the Right Questions?", The National Interest, 9 October 2019, en https://nationalinterest.org/blog/paul-pillar/donaldtrumps-syria-withdrawal-are-we-asking-right-questions-86906

Poza Cano, David: “El derrumbe del 'statu quo' en Oriente Próximo: las estrategias de seguridad de Irán y Arabia Saudî”, Instituto Español de Estudios Estratégicos, Documento de

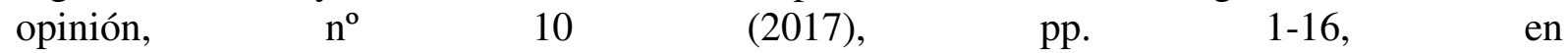
http://www.ieee.es/Galerias/fichero/docs_opinion/2017/DIEEEO10-

2017_OrienteProximo_DavidPoza.pdf

Priego Moreno, Alberto: "La nueva política exterior de Arabia Saudí”, Instituto Español de Estudios Estratégicos, Documento marco, $\mathrm{n}^{\mathrm{o}} 18$ (2015), pp. 1-20, en http://www.ieee.es/Galerias/fichero/docs_marco/2015/DIEEEM18-

2015_NuevaPoliticaExterior_ArabiaSaudi_A.Priego.pdf

Prieto Arellano, Fernando: "Choque de trenes en el mundo islámico. Repercusiones geoestratégicas de la ruptura de relaciones entre Arabia Saudí e Irán”, Instituto Español de Estudios Estratégicos, Documento de opinión, $\mathrm{n}^{\mathrm{o}} 28$ (2016), pp. 1-17, en http://www.ieee.es/Galerias/fichero/docs_opinion/2016/DIEEEO28-

2016_ChoqueTrenes_MundoIslamico_ArabiaSaudi_PrietoArellano.pdf

Reinares, Fernando: “A menos Estado Islámico, más al-Qaeda”, Real Instituto Elcano, Blog Elcano, 28 de marzo de 2019, en https://blog.realinstitutoelcano.org/a-menos-estado-islamicomas-al-qaeda/

-: "Turquía y la amenaza terrorista del Estado Islámico", Real Instituto Elcano, Comentario Elcano, $n^{\circ} 56 / 2015,22$ de octubre de 2015, en 
http://www.realinstitutoelcano.org/wps/portal/rielcano_es/contenido?WCM_GLOBAL_CON TEXT=/elcano/elcano_es/zonas_es/comentario-reinares-turquia-y-la-amenaza-terrorista-delautodenominado-estado-islamico

Rooney, Mildred: “El 'Estado Islámico': la ruta a la autoproclamación de un califato contemporáneo", Agenda Internacional, vol. 34 (2016), pp. 49-76

Sánchez Tapia, Felipe: "El futuro de Siria se juega en Idlib", Instituto Español de Estudios Estratégicos, Documento de análisis, $\mathrm{n}^{\mathrm{o}} 19 \quad(2020)$, pp. 1-20, en http://www.ieee.es/Galerias/fichero/docs_analisis/2020/DIEEEA19_2020FELSAN_Idlib.pdf

Shabbir, Fahad: "Riyadh Reaffirms Support For Syrian Settlement In Interests Of 'Brotherly' Nation", Urdupoint, 10 March 2021, en https://www.urdupoint.com/en/world/riyadhreaffirms-support-for-syrian-settlemen-1190115.html

Singh, Michael: "U.S. Policy in the Middle East amid Great Power Competition", The Washington Institute for Near East Policy, 30 March 2020, en https://www.washingtoninstitute.org/policy-analysis/us-policy-middle-east-amid-great-powercompetition

Smith, Amelia: "Iraqi vice-president on Sunni oppression, Nouri al-Maliki and sectarian division", Middle East Monitor, 28 August 2014, en https://www.middleeastmonitor.com/20140828-iraqi-vice-president-on-sunni-oppressionnouri-al-maliki-and-sectarian-division/

Thornton, Rod: "Countering Prompt Global Strike: The Russian Military Presence in Syria and the Eastern Mediterranean and Its Strategic Deterrence Role", The Journal of Slavic Military Studies, vol. 32, nº 1 (2019), pp. 1-24

Ülgen, Sinan y Kasapoğlu Can: “Operation Olive Branch: A Political - Military Assessment”, EDAM, January 2018, $\mathrm{n}^{\mathrm{o}}$ 2018/2, en https://edam.org.tr/wpcontent/uploads/2018/01/Operation-Olive-Branch-01.pdf

-: “Operation Euphrates Shield: Aims and Gains”, Carnegie Europe, 19 January 2017, en https://carnegieeurope.eu/2017/01/19/operation-euphrates-shield-aims-and-gains-pub-67754

UNHCR, Syria Refugee Crisis Explained, 5 February 2021, en https://www.unrefugees.org/news/syria-refugee-crisis-explained

Walt, Stephen M.: "ISIS as Revolutionary State: New Twist on an Old Story”, Foreign Affairs, November/December 2015, en https://www.foreignaffairs.com/articles/middle-east/isisrevolutionary-state

Zelin, Aaron y Knights, Michael: "The Islamic State's Resurgence in the COVID Era? From Defeat to Renewal in Iraq and Syria", The Washington Institute for Near East Policy, 29 May 2020, en https://www.washingtoninstitute.org/policy-analysis/islamic-states-resurgence-covidera-defeat-renewal-iraq-and-syria 